\title{
Formas de sacralizar a la figura real entre los mayas
}

How the Maya sacralised the image of the king

Des manières de sacraliser l'image du roi chez les Mayas

Daniel Salazar Lama

\section{OpenEdition}

\section{Journals}

Edición electrónica

URL: https://journals.openedition.org/jsa/14397

DOI: $10.4000 /$ jsa. 14397

ISSN: 1957-7842

Editor

Société des américanistes

Edición impresa

Fecha de publicación: 31 diciembre 2015

Paginación: 11-49

ISSN: 0037-9174

Referencia electrónica

Daniel Salazar Lama, «Formas de sacralizar a la figura real entre los mayas», Journal de la Société des américanistes [En línea], 101-1 et 2 | 2015, Publicado el 15 marzo 2016, consultado el 24 febrero 2023. URL: http://journals.openedition.org/jsa/14397 ; DOI: https://doi.org/10.4000/jsa.14397

All rights reserved 


\title{
Formas de sacralizar a la figura real entre los mayas
}

\author{
Daniel Salazar Lama*
}

Los fundamentos ideológicos utilizados por los gobernantes mayas en el ejercicio y la legitimación de su poder ante la sociedad, se ven reflejados en el arte de su época, donde estos personajes adquieren el protagonismo y se configuran como ejes temáticos de complejas escenas y grandes programas escultóricos de carácter público, en los que se les muestra como seres sagrados, capaces de dominar fuerzas y ciclos naturales. El presente estudio tiene por finalidad identificar los distintos rasgos iconográficos y los conceptos generados alrededor de la figura del gobernante en la escultura integrada en la arquitectura del Clásico temprano en las Tierras Bajas; forma escultórica que, para la época, es una de las expresiones más elaboradas de la exaltación y glorificación de los soberanos mayas. [Palabras clave: mayas, Tierras Bajas, gobernantes, Clásico temprano, escultura integrada en la arquitectura, iconografía, ideología.]

How the Maya sacralised the image of the king. Classic Maya art reflects the ideology used by Maya rulers to exercise and legitimate their power over society. On sculptural supports, the rulers stand as the leading figure and the main axis structuring complex scenes and iconographic programs of public nature, where they are represented as sacred beings able to dominate the forces of nature and the cycles of life. The present study aims to identify the various iconographic traits as well as the concepts generated around the figure of the ruler in Lowlands' architecture-integrated sculpture during the early Classic - a sculptural format that is one of the most elaborate expressions of glorification and exaltation of the Maya rulers. [Key words: Maya, Lowlands, rulers, early Classic, sculpture integrated into architecture, iconography, ideology.]

Des manières de sacraliser l'image du roi chez les Mayas. Les ressorts idéologiques que les dirigeants mayas ont mobilisés pour exercer et légitimer leur pouvoir vis-à-vis de la société sont visibles dans les œuvres d'art de leur époque. Dans celles-ci, ces personnages se donnent un rôle central et se présentent comme les piliers de scènes complexes et de grands programmes sculpturaux à caractère public : ils y apparaissent comme des êtres sacrés, capables de dominer les forces de la nature et les cycles de

* Posgrado en Estudios Mesoamericanos, Unam, Centro de Estudios Mexicanos y Centroamericanos (CЕMCA) [danielsalazarlama@gmail.com]. 
celle-ci. Le présent travail vise à identifier les différents traits iconographiques et les concepts qui ont été agglutinés autour de l'image du roi dans les sculptures intégrées à l'architecture du Classique ancien dans les Basses Terres. Ce format sculptural fut, en effet, à cette époque, une des formes d'expression les plus élaborées ayant servi à l'exhaltation et à la glorification des souverains mayas. [Mots-clés: Mayas, Basses Terres, gouvernants, Classique ancien, sculptures intégrées à l'architecture, iconographie, idéologie.]

\section{Introducción}

El objeto de estudio de la presente investigación es la escultura integrada en la arquitectura de las Tierras Bajas mayas, principalmente la de los períodos Preclásico tardío (400 a.C.-250 d.C.) y Clásico temprano (250-600 d.C.), sobre la cual se realizará un análisis iconográfico enfocado en las representaciones de los gobernantes y demás miembros de la realeza. Se definirá como escultura integrada en la arquitectura (EIA) a todos los programas escultóricos incorporados a una composición arquitectónica ${ }^{1}$. Para las épocas contempladas, las formas más comunes son los mascarones en la sección frontal de los cuerpos escalonados de los basamentos piramidales, las cresterías y los frisos esculpidos o modelados, y los bajorrelieves de estuco. En la mayoría de los casos estos programas escultóricos son de carácter público, ubicados en las fachadas exteriores de los edificios, de frente a grandes plazas públicas y generalmente a una altura más o menos considerable, lo que favorece su visibilidad a pesar de la distancia.

Muchos estudios enfocados en la EIA del Preclásico coinciden en señalar que son cinco las entidades divinas que se representan con mayor frecuencia: K'inich, el dios solar; el dios del maíz; la Deidad Ave Principal (llamada también Gran Ave Celestial); Chaahk, el dios de la lluvia y la montaña zoomorfa

1. Luis Sanz Castro (1997, p. 10-11) utiliza el término « escultura arquitectónica » para referirse a cualquier trabajo escultórico añadido a una superficie arquitectónica. Considero que la terminología y la definición empleada por ese autor son vagas al incluir bajo esta expresión todas las variantes formales, de manufactura y de integración al espacio que presentan estas esculturas.

Si se reserva la terminología « escultura arquitectónica » a los elementos arquitectónicos estructurales (dinteles, jambas, etc.) que recibieron un tratamiento escultórico, las demás esculturas que se associan a la arquitectura pueden ser consideradas como « esculturas integradas en la arquitectura $»$. Para definir este tipo de esculturas he elegido emplear el término " programa escultórico » por ser más apto para hacer referencia a un trabajo en relieve con características formales y compositivas, acervos iconográficos y contenidos temáticos específicos, y en cuya producción se hizo necesaria una serie de operaciones técnicas. Por su parte, « composición arquitectónica » alude a la disposición y el arreglo de las partes de una construcción; partes que al ser originalmente pensadas - o posteriormente adecuadas - para albergar determinados programas escultóricos cumplen con ciertas características y requerimientos constructivos. Es necesario aclarar que he decidido dejar de lado y no emplear el término « decoración arquitectónica » por tratarse de una expresión que alude a la finalidad de una obra como mera ornamentación, lo que de entrada dificulta la comprensión que podemos tener de este tipo de esculturas. 
(Figura 1)2. Investigadores como Stone y Zender (2011, p. 123) y Stuart (citado en Houston 2004, p. 303) han sugerido que algunos de los mascarones del Preclásico podrían ser antropónimos reales monumentales. Como lo menciona Houston (ibid.), muchos de los elementos clave de estas imágenes se han perdido, lo que impide cualquier tipo de « lectura ». Además, algunos de sus elementos iconográficos componentes conforman un acervo iconográfico común en varios retratos de deidades, lo que invalida la idea de que sean signos con una lectura fonética que responda a un nombre en particular. Coincido con Sanz Castro (1998a), Houston (2004) y Carrasco (2005) en considerar estos programas escultóricos del Preclásico como representaciones de espacios geo-míticos y de sus habitantes sobrehumanos.
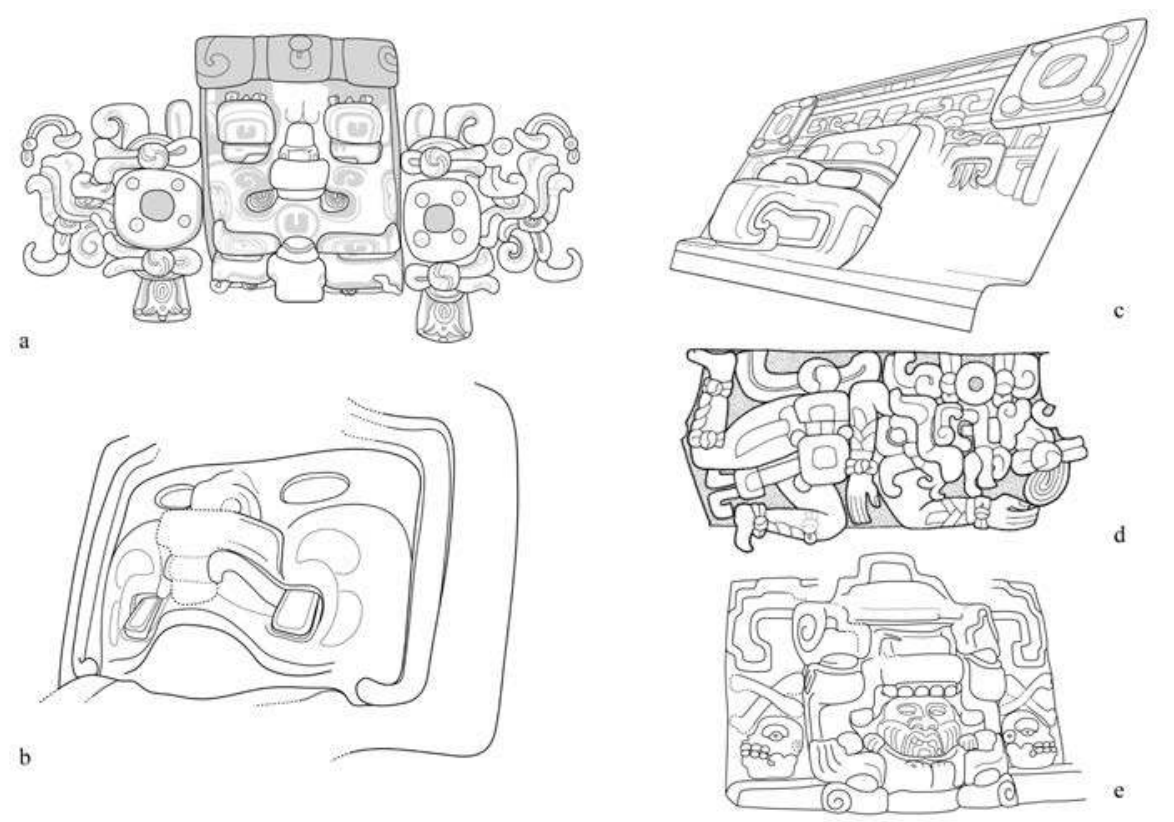

Fig. 1 - a. Mascarón del dios K'inich. Estructura 5C-2nd de Cerros; basado en dibujo de L. Schele, en Freidel y Schele (1988b); b. Mascarón del dios del maíz. Subestructura IIC-2, Calakmul; basado en fotografía del autor; c. Mascarón de la Deidad Ave Principal, Estructura 1, Nakbé; basado en boceto reconstructivo de T. W. Rutledge, en Hansen (1992); d. Chaahk, friso de la Subestructura IIC, Calakmul. Dibujo de S. Martin, tomado de García

Barrios (2009); e. Mascarón de la montaña zoomorfa con un dios viejo emergiendo de sus fauces, Estructura B-1 de Holmul; basado en dibujo previo de A. Tokovinine, cortesía del autor. Dibujos a, b, c y e de Daniel Salazar.

2. Consultar Hansen $(1992,1998)$; Luis T. Sanz Castro (1997 y 1998a); Michael D. Carrasco (2005); Ana García Barrios (2007 y 2009); Francisco Estrada-Belli (2006 y 2011), entre otros. 
A diferencia de estos seres y criaturas que presentan rostros con rasgos no humanos bastante acentuados o rostros enteramente zoomorfos, algunos de los protagonistas de la EIA del Clásico temprano tienen rasgos fisonómicos completamente humanos, o una fusión de estos y características formales de los dioses (Figura 2). Esta particularidad de la EIA del Clásico sumada al complejo iconográfico relacionado con el poder político y en algunos casos junto a jeroglíficos nominales que aluden a gobernantes registrados en las inscripciones, sugiere que desde el comienzo de la época clásica la EIA experimentó una reorientación temática y pasó gradualmente a enfocarse en los miembros de la realeza, principalmente los gobernantes.
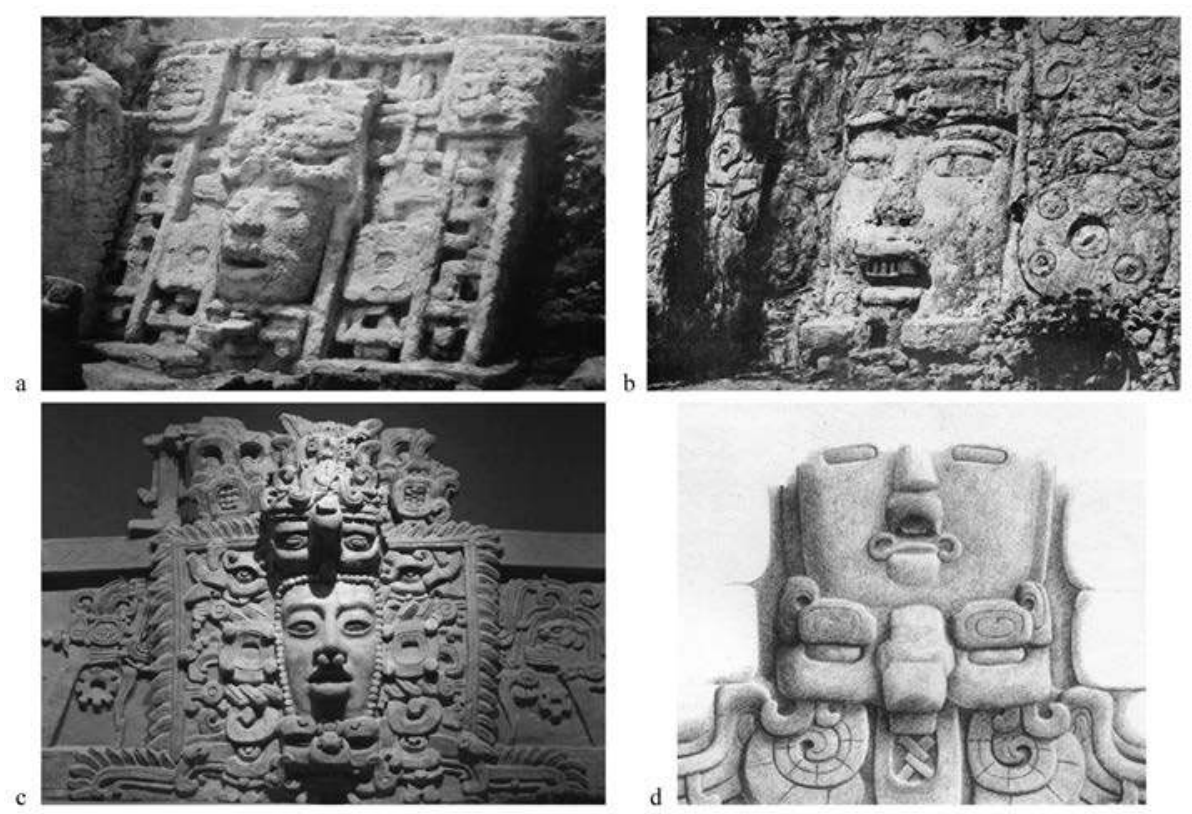

Fig. 2 - a. Mascarón de Estructura N9-56, Lamanai. Fotografía tomada de Segovia Pinto (1981); b. Mascarón de la Estructura Kabul, Izamal. Fotografía de D. Charnay (1863), publicada en www.amphilsoc.org; c. Friso de Placeres (detalle). Fotografía de Daniel Salazar; d. Mascarón « Ajaw », Estructura 5D-232nd, Tikal. Dibujo reconstructivo de W. Coe, tomado de Valdés (1991).

Al respecto, es preciso retomar el señalamiento hecho por Juan Antonio Valdés en su estudio sobre los mascarones del Grupo 6C-XVI de Tikal:

Los cambios sociopolíticos que en las tierras bajas dieron inicio al periodo clásico, se reflejan también en los mascarones asociados a la arquitectura del momento, comenzando a desaparecer la utilización de complejos motivos sobrenaturales, para dar paso a una nueva forma de estilo en el uso de las grandes máscaras, en 
donde vino a generalizarse el proceso de divinización de los gobernantes como elemento central de la figura. (Valdés 1991, p. 141)

Un claro indicador de la dimensión y el estatus de los gobernantes del periodo Clásico (250-900 d.C.) es el título K’uhul Ajaw, « Señor Sagrado ». David Stuart (2005, p. 265) sugiere que el adjetivo k'uhul define a los gobernantes como encarnaciones o conductos de lo sagrado, mientras el término $k$ ' $u$ h hace referencia a los dioses y entes divinos del cosmos (ver Houston y Stuart 1996, p. 295; Stuart et al. 1999, p. 138-142). Por su parte, Alfredo López Austin (1994 [2000], p. 35) ha planteado que entre los mexicas, así como a nivel mesoamericano en general, el ser humano « [...] era imaginado como un compuesto en el que intervenían varias entidades anímicas de funciones particulares, naturalezas distintas y diferentes orígenes ». Así, el cuerpo podía alojar circunstancialmente multitud de energías y fuerzas naturales, aunque solamente los gobernantes y los personajes más sobresalientes de las élites tenían la capacidad de albergar a - o ser poseídos por - entidades divinas. En concordancia con esta idea, algunas escenas del Clásico muestran a los miembros de la realeza en eventos de personificación, adquiriendo ciertos atributos y rasgos de la identidad de los dioses en un proceso de concurrencia entre un agente humano y una entidad sobrenatural o un dios (ver Houston et al. 2006, p. 270-271; Knub et al. 2009; Velásquez García 2010a).

Por otra parte, para los mayas del Clásico, al igual que para muchas culturas mesoamericanas, la naturaleza de los dioses es mutable; tienen la capacidad de pasar del anecúmeno al ecúmeno y adaptarse a las reglas de cada ámbito ${ }^{3}$; pueden fusionarse en un mismo ser o separarse (fisión) en entes distintos, respondiendo a aspectos particulares de su personalidad (Martin 2006a; Valencia Rivera 2013). Se trata de los seres que originalmente imprimieron forma y dinamismo al cosmos a través de actos cosmogónicos y hazañas heroicas (López Austin 1990 [2006], Cap. 10-12). No por esto los dioses fueron concebidos como seres abstractos, remotos y opuestos a la naturaleza humana: en cierta medida compartían algunos aspectos del desarrollo cíclico del hombre; nacieron en un tiempo determinado, necesitaban sustento y eventualmente podían morir, como los astros, la vida natural y los seres humanos. Su aspecto, en muchos casos distinto del de los hombres, es un compendio de atributos formales con contenidos simbólicos relativos a sus capacidades sobrehumanas ${ }^{4}$.

3. Siguiendo las definiciones de Alfredo López Austin y Leonardo López Luján (2009, p. 43), se entenderá anecúmeno como « el tiempo-espacio propio de los dioses y los muertos, y ajeno a las criaturas », mientras que ecúmeno se definirá como « el mundo habitado por criaturas, aunque también está ocupado definitiva o transitoriamente por seres sobrenaturales ».

4. Los rasgos principales de algunos dioses que se analizarán en el presente estudio son: para la deidad solar, marcas del signo $k$ 'in (sol) sobre el cuerpo, ojos rectangulares con pupilas esquinadas y facciones de felino; para Chaahk, rizos acuáticos como nubes en la cabeza, rasgos de ofidio, un nudo de tela como pectoral y el pelo recogido sobre la frente; por su 
Regresando a la EIA del Clásico temprano, la consolidación del cambio temático señalado por Valdés (1991), Sanz Castro (1998a, p. 107) y Freidel y Schele (1988a), se da con la progresiva aparición de la imagen de personajes humanos (gobernantes) ocupando el lugar de los dioses. En torno a estos retratos se colocaron de forma recurrente elementos iconográficos y arreglos compositivos y arquitectónicos que logran configurar, gracias a su consistencia y repetitividad a lo largo del período, un modelo o patrón de representación.

La finalidad de este trabajo es identificar y analizar dicho patrón, tomándolo como una serie de recursos gráficos, compositivos y espaciales empleados en la construcción de la imagen de los gobernantes en la EIA; recursos que llamaremos « formas de representación ». Como parte del análisis se buscarán los valores simbólicos contenidos en estas formas de representación y la manera en la que significan a la figura real; consecuentemente, se indagará acerca de las posibles implicaciones ideológicas que tuvo el patrón para la sociedad maya en general.

El estudio se realizará tomando como base siete formas de representación.

Forma 1. La ubicación del retrato de los gobernantes en fachadas arquitectónicas monumentales

Durante el Clásico temprano la imagen de gobernantes y antepasados reales como protagonistas en las escenas de los frisos y mascarones vino a ocupar los espacios arquitectónicos destinados en el periodo anterior a temas y seres sobrenaturales. Esta continuidad en el uso de espacios compositivos dentro de la arquitectura sugiere una recurrencia en la necesidad de significar el lugar y el entorno construido a través de programas iconográficos de carácter público. Durante el Preclásico, la presencia de deidades y seres sobrenaturales en la EIA denota la preocupación por replicar a escala humana la estructura y la dinámica del cosmos. Para el Clásico temprano, en cambio, la imagen de la figura real determina la función de los recintos como lugares de culto y rememoración de los antepasados o como sedes del poder (Figura 3a).

Para el Preclásico tardío es viable pensar que los gobernantes se integraban presencialmente a las estructuras cosmológicas recreadas en la arquitectura ceremonial, como el edificio 5C-2nd de Cerros (Freidel y Schele 1988b) o los Conjuntos Tipo E (Figura 3b). Esto les permitía adquirir ante el pueblo el poder de controlar el tiempo, las lluvias, las cosechas y demás fenómenos

parte, la Deidad Ave Principal tiene ojos cuadrados y las marcas de día/sol y noche ( $k$ 'in y $a k^{\prime} a b$ ) en el plumaje de alas serpentinas extendidas; K' awiil lleva una hacha de jade humeante incrustada en la frente y rostro de reptil, mientras que el dios del maíz, con ojos oblicuos, dientes y colmillos prominentes, posee una cabeza que por su forma y por las foliaciones que emergen de ella simula una mazorca. El aspecto de los dioses mayas varía considerablemente entre los distintos períodos (Preclásico, Clásico y Posclásico). Para ver a detalle las características formales diagnósticas de algunos dioses consultar Bardawil (1976); Taube (1992, 1996); Hellmuth (1987); García Barrios (2007, 2009); Martin (2006a), entre otros. 
naturales (García Capistrán 2013). En la EIA de estos períodos los retratos de gobernantes como protagonistas de las escenas son escasos ${ }^{5}$.

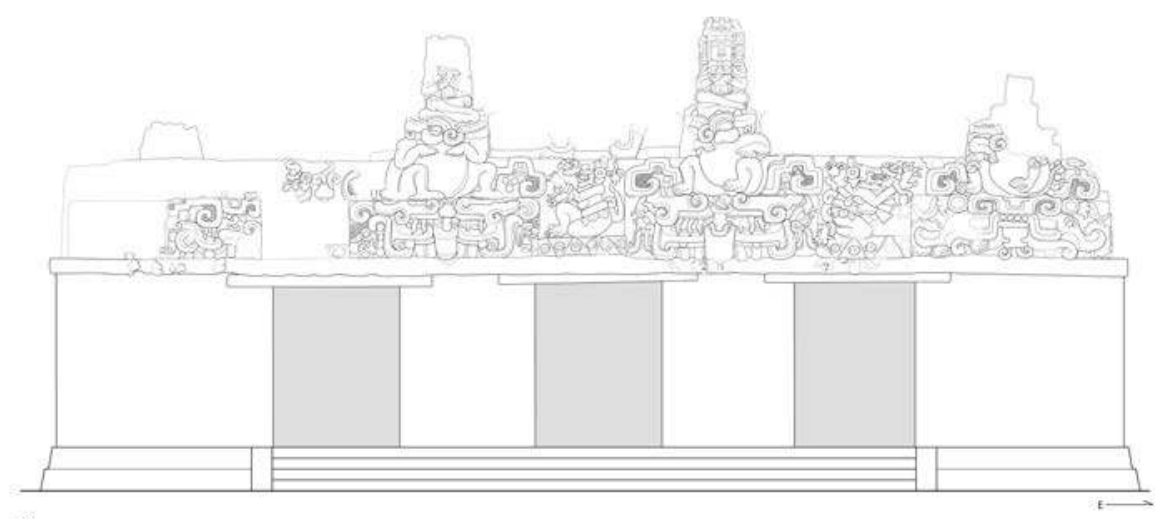

a

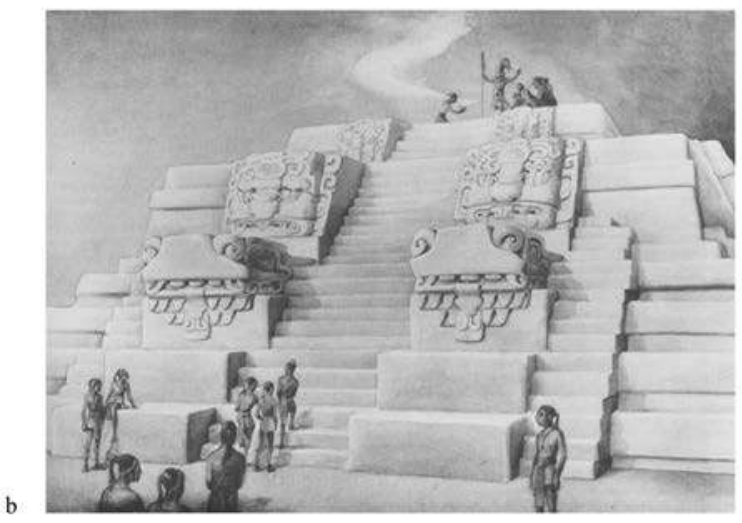

Fig. 3 - a. Palacio I-A Sub y su friso, Balamkú (Clásico temprano). Dibujo de Daniel Salazar, tomado de Salazar Lama (2014); b. Dibujo reconstructivo e interpretativo de la Estructura E-VII, Uaxactún (Preclásico tardío).

Dibujo de T. Proskouriakoff. Tomado de Proskouriakoff (2002).

5. Ejemplos del Preclásico con gobernantes como protagonistas son los mascarones 1 y 2 de la Plataforma 1C de El Tigre, Campeche (150 a.C.-250 d.C.). Sus rasgos enteramente antropomorfos y la falta de referencias iconográficas o características fisonómicas que refieran a deidades permiten sugerir que se trata de retratos tempranos de gobernantes (consultar Vargas Pacheco 2010). Otro ejemplo es el relieve de estuco del Complejo El Tecolote en El Mirador, Guatemala (ver forma de representación n. ${ }^{\circ} 6$ ). 


\section{Forma 2. El uso de un lenguaje corporal y gestual hierático y rasgos fisonómicos estilizados}

El lenguaje corporal de los gobernantes en la EIA constituye un código visual que establece la jerarquía de los personajes y la naturaleza de los individuos retratados. Los ejemplos de EIA de cuerpo completo conservados muestran un alto nivel de estandarización en la postura y el lenguaje gestual empleado. El friso del palacio 1-A Sub de Balamkú (550 d.C. aprox.) conserva hoy día la representación de dos gobernantes sentados con las piernas cruzadas y los brazos y las manos sobre el pecho, con gesto de sostener una barra ceremonial (Figuras 4a y b); el personaje del mascarón de la Plataforma 2 de Toniná (450-600 d.C.) y los del friso del Edificio A, Grupo II de Holmul (600 d.C.) (Figuras 14d y 4c) tienen las manos apoyadas sobre las piernas dobladas, y en el relieve de Tutil II en Dzibanché (550 d.C. aprox.) el protagonista sostiene con los brazos dos antorchas en posición diagonal (ver Velásquez García 2011, Fig. 5a y b).

Elizabeth Benson (1974, p. 111) opina que la postura de las piernas cruzadas es una posible herencia de las esculturas olmecas del Preclásico temprano y medio, adoptada por individuos emblemáticos en el arte maya y utilizada para indicar autoridad y alto rango. La posición frontal del cuerpo y del rostro es, según Erik Velásquez García (2011, p. 422-423, 427), una pose estática desarrollada en torno a la figura de los gobernantes, empleada para denotar grandeza y majestuosidad, lo atemporal y lo arquetípico ${ }^{6}$.

Este código del lenguaje corporal del Clásico temprano está acompañado de rasgos fisonómicos estandarizados y sumamente esquemáticos (Figura 2) ${ }^{7}$. Dentro del corpus de mascarones de este período el aspecto de los gobernantes es en gran medida similar, alejándose de una intención retratista y respondiendo a un ideal del rostro del gobernante (comparar Figuras 2 a y 2b). Presentan algunas facciones atenuadas de la deidad del maíz, como el labio superior ligeramente prominente y los ojos rasgados. Estos rasgos del dios del maíz del Clásico (Figura 5), imagen por excelencia de un dios joven y bello (Taube 1985; Bassie-Sweet 2002), se originan en el arte olmeca y se acentúan en la época preclásica maya (Figuras $1 \mathrm{~b}$ y $9 \mathrm{a})^{8}$.

6. Tatiana Proskouriakoff (1950, p. 28-29) asegura que las piernas cruzadas y el torso en posición frontal es propia del Clásico tardío; sin embargo, nuevos descubrimientos sugieren que ya estaba presente por lo menos hacia mediados o finales del Clásico temprano.

7. Uno de los primeros mascarones con un rostro humano con facciones sumamente esquematizadas es el ejemplar encontrado en la Estructura 5D-23-2 de la Acrópolis Norte de Tikal (Figura 2D), fechado hacia el 200-225 d.C., es decir, en los albores del Clásico temprano (Sanz Castro 1997, p. 104-105).

8. Para enterarse de los rasgos del dios del maíz y de su evolución a partir del arte olmeca, consultar Taube (1996). 


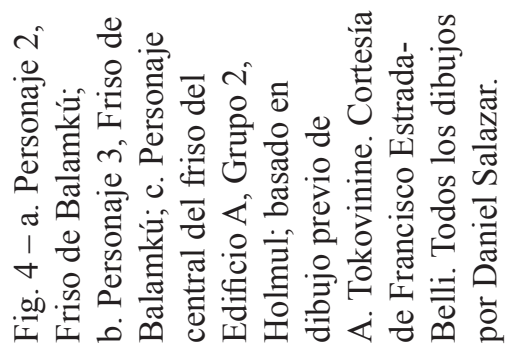
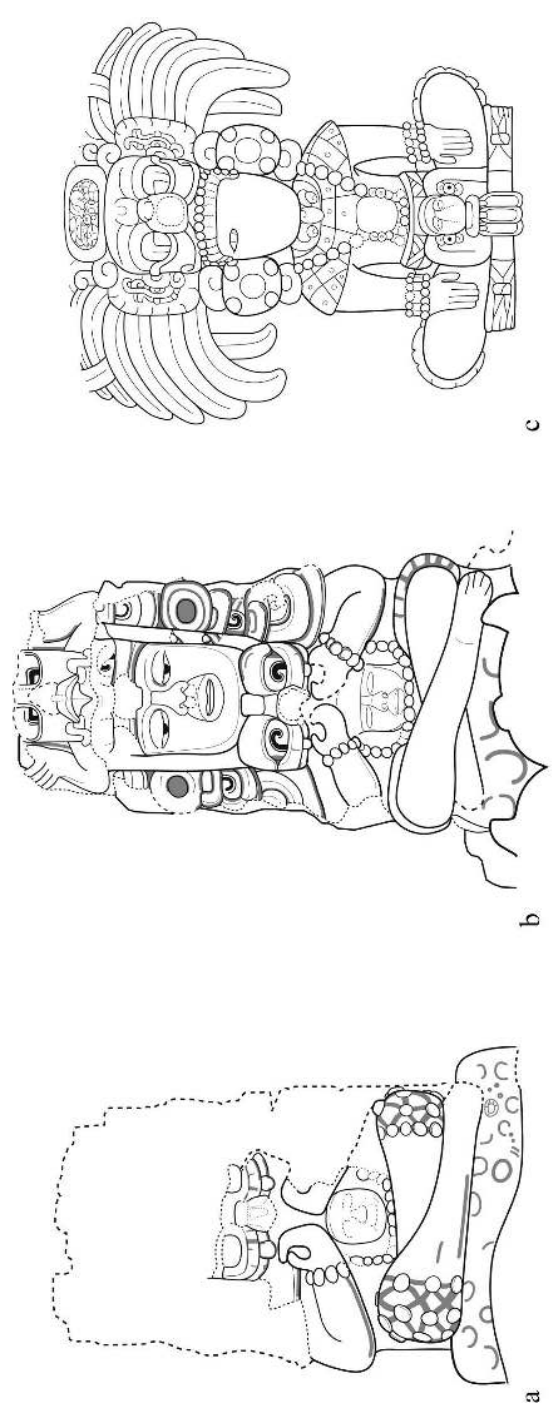

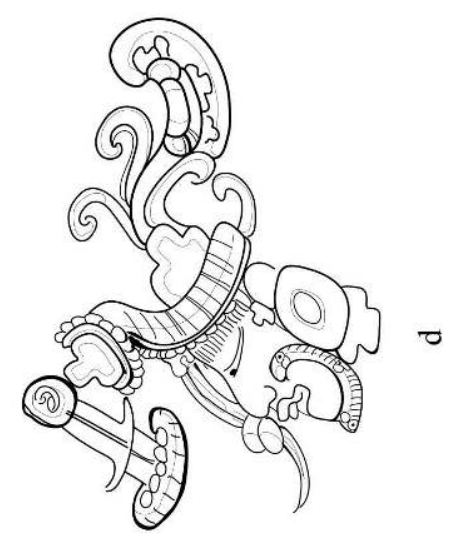

สี

ช.

जी

造产完

需言要

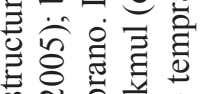

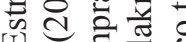

๘ $\approx$ च

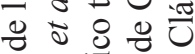

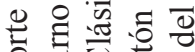
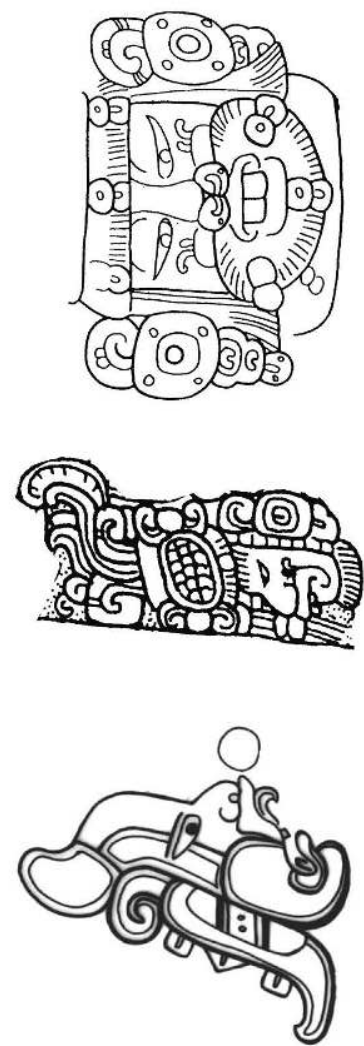

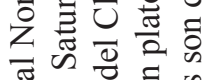

풀 $\sum$ 를 छ

ब

추

छ

甲 $\ldots$

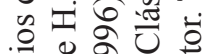

คํํㄹ

ช. 윸웡

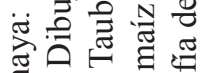

ఏ

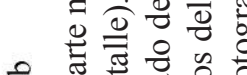

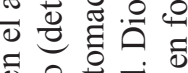

ชิ 오무

츨

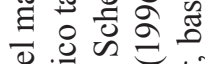

व.

की

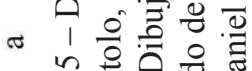

n 을 을

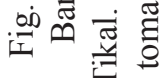

वี 
Es necesario hacer énfasis en la importancia que se le da al rostro y a la cabeza en la EIA del Clásico temprano. Concuerdo con Houston y Stuart (1998, p. 83) y con López Austin (2012, p. 197-220), quienes proponen que en el pensamiento maya y mesoamericano en general estas partes del cuerpo son vistas como la manifestación esencial del ser, la personalidad y la identidad. Sugiero que a través de los rasgos fisonómicos y de los elementos iconográficos alrededor del rostro en los retratos monumentales de gobernantes, se despliega una gama de recursos que evidencian y señalan de forma tangible las características y los detalles que individualizan a estos seres como personas, revelando su naturaleza y sus atributos.

\section{Forma 3. La utilización de componentes del atavio de los dioses y símbolos del poder real}

Para su análisis, estos componentes serán separados de la siguiente manera: « atavío de rostro », elementos de vestimenta y accesorios asociados al poder político.

En el caso de los mascarones, el arreglo compositivo estandarizado de elementos alrededor del rostro y de la cabeza será referido como « atavío de rostro » (Figura 6). Durante el Clásico temprano un arreglo similar también forma parte de la imagen de algunos dioses representados en la EIA y en los incensarios efigie de las fases cerámicas Tzakol I-III del Petén Central (Figura 7; Hellmuth 1987). Para el Preclásico, las primeras versiones del atavío de rostro son menos complejas, y acompañan los retratos de dioses como K'inich y Chaahk.

De forma general, en la EIA del Clásico temprano es común encontrar que el rostro de los gobernantes está rodeado de una hilera de cuentas de jade y, a veces, todo el atavío de rostro dentro de un marco de plumas. La combinación de ambos elementos se ve en los rostros de los frisos de Placeres y del edificio Pimiento en Xultún (450-600 y 250-378 d.C. respectivamente) (Figuras 8A y B), en los incensarios efigie del dios GI del Petén central (Figura 7C) y en el mascarón de K'inich en la Subestructura Azul, en la Acrópolis de Copán?. El jade y las plumas, por ser objetos preciosos y de prestigio, se asocian al poder real, al estatus y a un ideal de riqueza. Por el lazo simbólico entre el jade, el maíz y la fertilidad (Taube 2005), el uso de cuentas como joyas indica atributos compartidos entre soberanos y dioses, ligados a su calidad de seres preciosos y poderosos.

El mascarón inferior del atavío de rostro en la mayoría de los casos corresponde a seres zoomorfos de naturaleza predominantemente terrestre o infra terrestre, como felinos o reptiles híbridos y criaturas acuáticas (Figuras 4A y B, 8 y 20), de los que el rostro del personaje parece emerger, similar a la manera en la que surgen el dios del maíz y el dios solar de las cabezas de criaturas

9. La imagen del mascarón de K'inich de la Subestructura Azul de Copán está disponible en Argucia Fasquelle y Fash 2005, Fig. 6.15. 


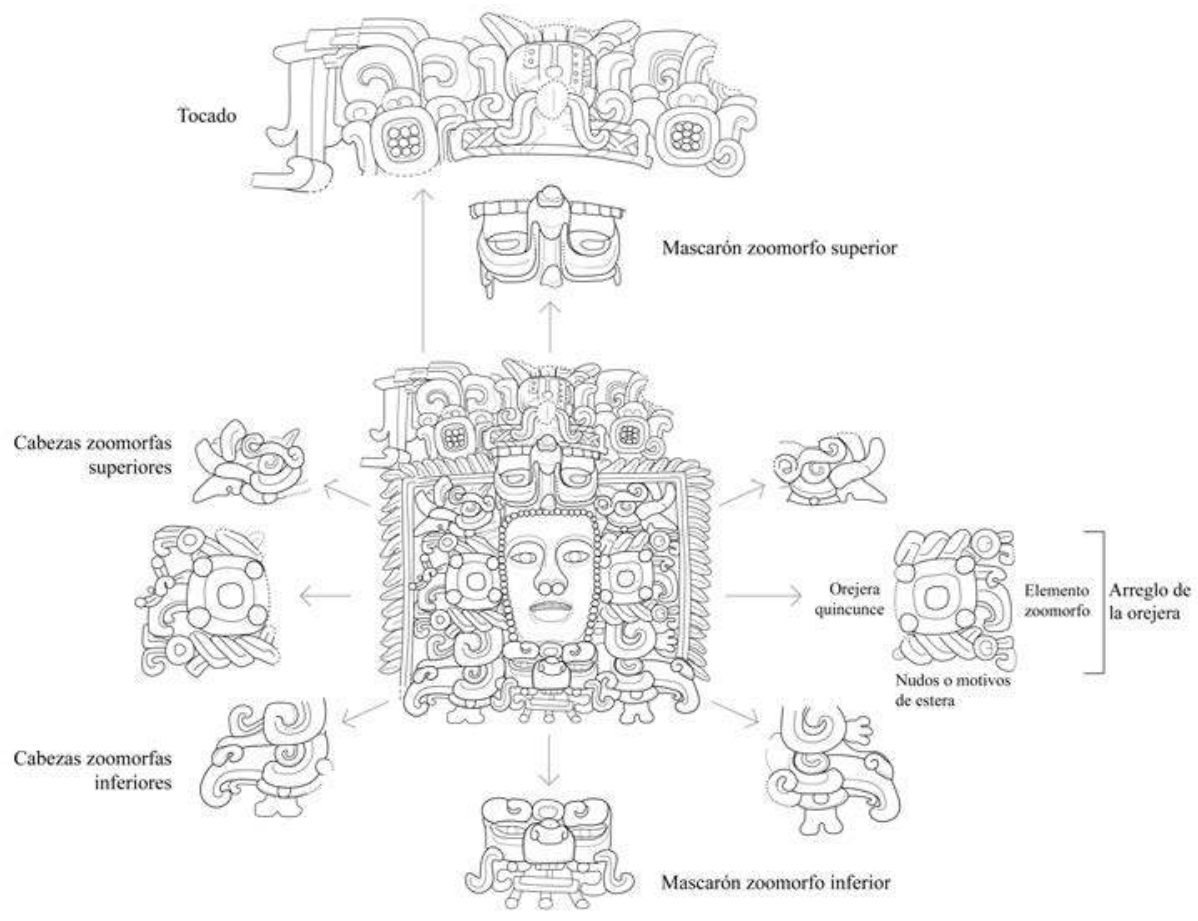

Fig. 6 - Atavío de rostro seccionado. Mascarón central del friso de Placeres. Dibujo de Daniel Salazar.

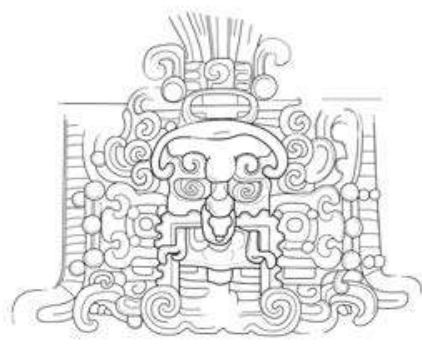

a

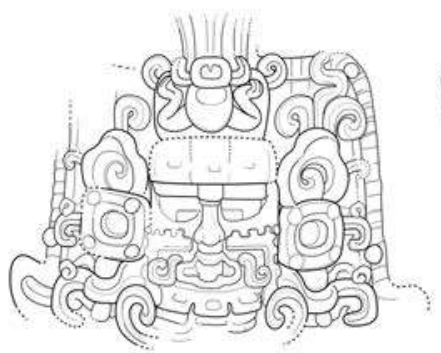

b

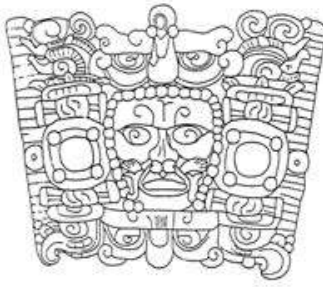

$\mathrm{c}$

Fig. 7 - a. Mascarón de Chaahk, friso del Templo del Sol Nocturno, El Zotz; basado en Houston et al. (2012); b. Mascarón de K'inich, friso del Templo del Sol Nocturno, El Zotz; basado en secuencia de imágenes presentadas en el video: http://video. nationalgeographic.com/video/news/guatemala-maya-sun-god-vin; c. Incensario efigie del dios GI. Tomado de Hellmuth 1987. Dibujos a y b de Daniel Salazar. 
emblemáticas que simbolizan la tierra (Figura 9). El mascarón superior, en cambio, es de naturaleza heterogénea, puede representar a un dios específico que alude a un posible evento de personificación por parte del gobernante ${ }^{10}$, a criaturas zoomorfas que indican alguna característica o atributo del personaje o, más puntualmente, puede tratarse de la Gran Ave Celestial (ver Figuras 8A y $17 \mathrm{~A})^{11}$. Las cabezas zoomorfas de perfil arriba y debajo de las orejeras son por lo general recurrentes (ver Figura 6): abajo se encuentra la Serpiente de Lirio Acuático (o serpiente Witz' - ver Stuart 2007) ${ }^{12}$, criatura que al ser la personificación del agua terrestre y subterránea (ríos, corrientes y lagos) podría funcionar como una alusión al dominio sobre el agua que ejerce el gobernante, vinculada en otros contextos a la germinación o renacimiento del dios del maíz (Henderson 2010, p. 879-880); arriba de las orejeras se hallan cabezas del monstruo o pez Xook. Por su asociación con el dios GI y el Dios Remero Espina de Mantarraya, ambos seres relacionados al momento liminar del alba (Velásquez García 2010b), es posible que el pez Xook sea una referencia a la transfiguración en momentos liminares (Salazar Lama 2014, p. 125-126). Las orejeras, flanqueadas por nudos o por motivos trenzados de estera (símbolo del poder real), tienen generalmente cuatro puntos en las esquinas y un hueco circular al centro, representando un quincunce que indica el centro del cosmos y las cuatro direcciones periféricas.

Este conjunto de elementos (atavío de rostro) conforma una serie de referencias a los poderes especiales de los personajes; además, funciona como un esquema cosmológico cuyo propósito es resaltar la figura de los gobernantes, colocándolos en el centro del cosmograma ${ }^{13}$.

En la EIA del Clásico temprano son escasos los tocados conservados. Los personajes principales del friso de Holmul que aún presentan este elemento muestran arreglos de plumas similares a los de los tocados del Clásico tardío y la inclusión de jeroglíficos que expresan sus antropónimos (Figura 4C).

En cuanto a la vestimenta, son pocos los ejemplares de cuerpos humanos completos en buen estado de conservación que permiten identificar las piezas del

10. Acerca del uso del rostro de dioses como parte del tocado o colocados inmediatamente sobre la cabeza de personajes humanos como referencia a un evento de personificación, consultar Knub et al. (2009, p. 191).

11. Jesper Nielsen y Christophe Helmke (en prensa) consideran que la cabeza de esta ave colocada como parte de los tocados, puede aludir al episodio mítico de la derrota de la Deidad Ave Principal a manos de Jun Ajaw, con quién se identificaría el gobernante que la porta. Este episodio mítico se encuentra representado en su versión más completa en el mural poniente y parte del mural sur de la Estructura Sub IA de San Bartolo (consultar Saturno 2009).

12. Una clara excepción es el mascarón de Kabul, Izamal (250-450 d.C.), que presenta dos rostros de serpientes cuyos rasgos diagnósticos son distintos a los de la serpiente acuática (ver Burgos Villanueva, Palomo Carrillo y Kantún Rivera 2012, p. 214-215; Fig. 4 y 6).

13. Un cosmograma es la representación bidimensional o tridimensional de una parte o la totalidad de la estructura física del cosmos. 

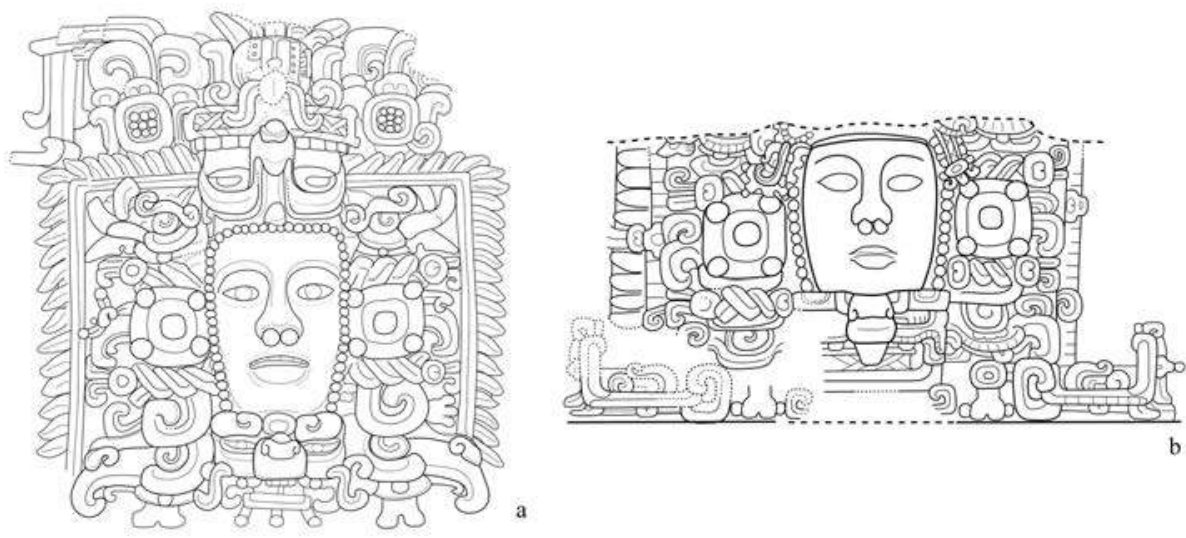

Fig. 8 - a. Mascarón central, friso de Placeres; b. Mascarón, friso del Edificio Pimiento, Xultún; basado en dibujo previo de Heather Hurst, en Saturno et al. (2012). Dibujos de Daniel Salazar.

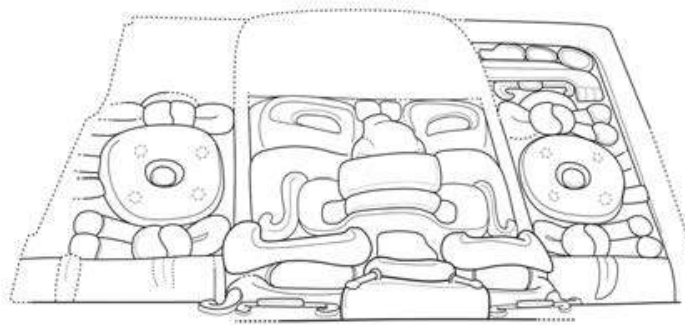

a

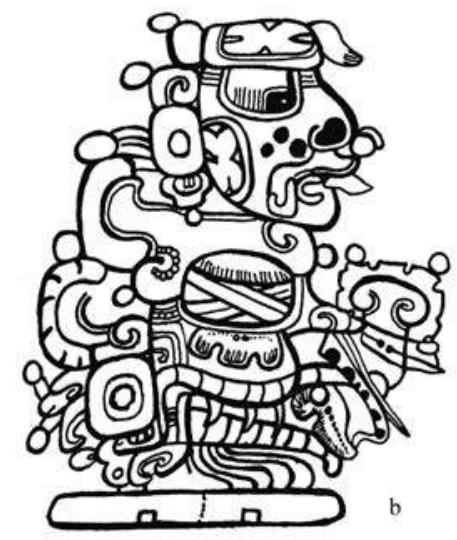

Fig. 9 - a. Mascarón del dios del Maíz, Estructura Nohochbalam, Chakanbakan, Q. Roo (Preclásico tardío). Dibujo de Daniel Salazar basado en estudio fotográfico del autor; $b$. K'inich sobre la cabeza de un cocodrilo terrestre (Clásico temprano). Tomado de Hellmuth (1987). 
atuendo. En el friso de Balamkú, el personaje 2 lleva una falda de red que alude al episodio y al lugar de renacimiento del dios del maíz (Figura 4A; consultar Quenon y Le Fort 1997), posible referencia a un evento de personificación del dios por parte del gobernante ${ }^{14}$.

En los frisos de Holmul y del edificio Pimiento en Xultún, y en uno de los segmentos de la crestería del Palacio de la Estelas de Kohunlich (250-450 d.C.) (Figuras 4C y 10A), los personajes principales tienen un traje sencillo de falda corta, cinturón adornado con pequeñas cabezas antropomorfas o zoomorfas de las que cuelgan celtas de jade, pectoral y collar de placas y cuentas de jade. Este traje y sus componentes forman parte del complejo iconográfico asociado al poder, y es parte del atuendo de los gobernantes en las estelas y en las celtas de jade del Clásico temprano (Figura 11).

En el mencionado relieve de estuco de Xultún y en la sección este de la crestería de Kohunlich (Figura 10B) los gobernantes portan barras ceremoniales de cuyos extremos emergen fauces abiertas de serpientes y ciempiés esqueléticos (comparar con Figura 11). Estas barras bicéfalas sirven para conjurar y materializar antepasados, dioses o criaturas sobrenaturales emblemáticas por medio de rituales y sacrificios (Stuart 1988); se trata de uno de los oficios más importantes de la realeza: la demostración de cómo el gobernante y los miembros de la corte se conectan y trabajan en conjunto con las fuerzas que dinamizan y mantienen el orden del cosmos (Clancy 1994).

\section{Forma 4. El uso de referencias a dioses como parte de los nombres-emblemas asociados a gobernantes}

Se considerará como emblema a una imagen u objeto que se usa para representar una noción o idea sobre una persona, y que muchas veces sirve como un ícono para identificarla. Al ser un nombre-emblema, esta imagen puede ser, además, la representación gráfica de su antropónimo. Este es un recurso poco común en la EIA del Clásico temprano. En la Acrópolis de Copán existen

14. El traje de red se encuentra fuertemente vinculado con las mujeres de élite de la esfera política del reino de Kanu'l, representadas en las estelas de Calakmul y de sus ciudades aliadas para el Clásico tardío (consultar García Barrios y Vásquez López 2012). Sin embargo, durante el Clásico existen imágenes de personajes que utilizan el mismo traje, pero sin referencia alguna al reino de Kanu'l, y sí como una clara alusión al episodio del renacimiento del dios del maíz (ej. el panel de Yomop [ver Le Fort 1995]; la lápida del Templo de las Inscripciones y los paneles del Templo de la Cruz Foliada, ambos en Palenque). El uso de elementos de la vestimenta de los dioses por parte de los gobernantes, en conjunto con otras referencias a episodios míticos específicos, es una forma de aludir a un evento de personificación de un dios (Knub et al. 2009, p. 191). Le Fort (sf) en un trabajo reciente, sugiere que solamente a través de un conjunto de elementos, a falta de expresiones textuales que así lo indiquen, se puede definir una escena como un evento de personificación. El friso de Balamkú cuenta con una serie de referencias que permiten suponer la personificación: la montaña mítica como localidad; el sapo híbrido que remite al acto del renacimiento y la falda enrejada o de red del personaje $\mathrm{N}^{\circ} 2$. 


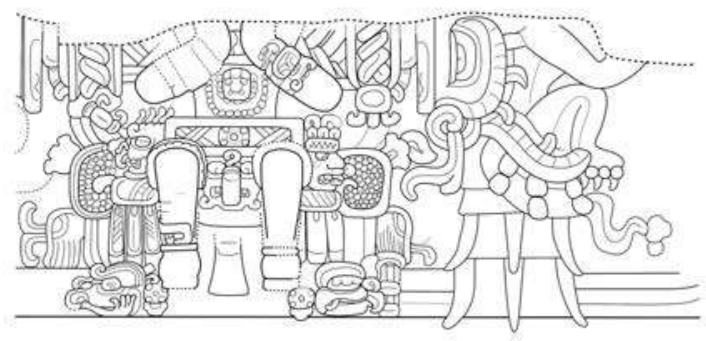

a

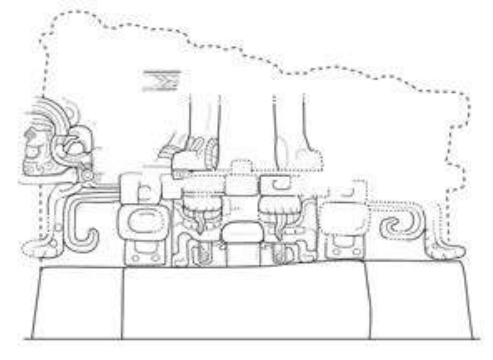

b

Fig. 10 - a. Personaje central, friso del Edificio Pimiento, Xultún; basado en dibujo previo de Heather Hurst, en Saturno et al. (2012); b. Sección 1

Este, crestería del Palacio de las Estelas, Kohunlich; basado en dibujo previo presentado en Zetina y Giráldez (1999). Dibujos de Daniel Salazar.
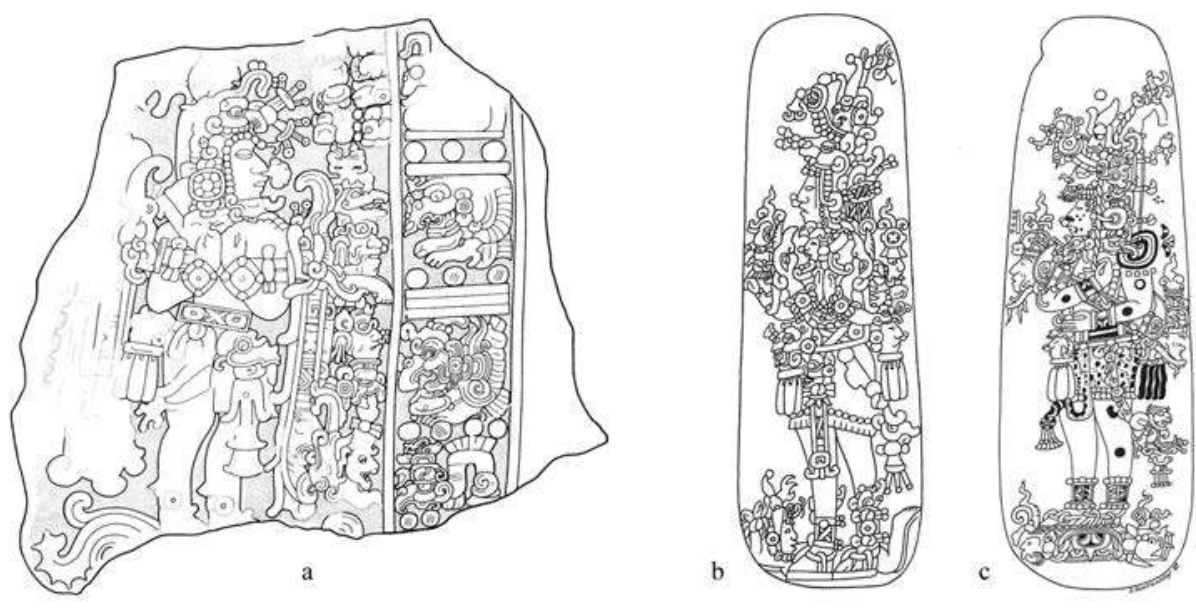

Fig. 11 - a. Estela 20, Caracol. Dibujo tomado de Fields y Reents-

Dubet (2005); b. « Celta de Leiden »; c. Celta de jade sin procedencia.

Dibujos b y c de J. Montgomery, disponibles en www.famsi.org 
dos casos paradigmáticos que ilustran muy bien el concepto: los relieves de estuco de la fachada poniente del edificio Margarita (437-472 d.C.) y los de los muros inferiores de la fachada norte de Rosalila (571 d.C.) (Figura 12). Ambas imágenes están constituidas por distintos elementos que se conjuntan para representar gráficamente el nombre-emblema del fundador de la dinastía gobernante de Copán, K’inich Yax K’uk Mo'. En los dos casos se fusionan el ícono del logograma YAX y las imágenes de una guacamaya (mo') y un quetzal ( $\left.k^{\prime} u k^{\prime}\right)$ con el rostro del dios K'inich para configurar el nombre del fundador (Taube 2000, p. 28-30; Martin y Grube 2002, p. 194; Argucia Fasquelle y Fash 2005, p. 222-223) $)^{15}$.

En estos ejemplos de Copán, los elementos que forman el nombre del personaje se presentan bajo la apariencia de motivos iconográficos, funcionando con reglas de composición propias de la imagen y no de la escritura. Sin embargo, como escenas o elementos iconográficos estas figuras no tienen mucho sentido, pero cobran total significado al considerarlas como las imágenes emblemáticas que describen gráficamente un antropónimo real.

Además de estos dos casos de Copán, existen los tocados nominales integrados al retrato de los gobernantes como una variante de los nombres-emblemas, considerados como tácticas comunicativas donde la línea divisoria entre la escritura y la imagen se desdibuja (Stuart 2013). Siguiendo con el ejemplo de K'inich Yax K'uk' Mo', este personaje retratado en el Altar Q de Copán - Clásico tardío - (Figura 13A) lleva su nombre en el tocado, configurado a partir de los mismos íconos ( $k$ 'uk' [quetzal] y mo' [guacamaya] en una sola figura) de los relieves de estuco de Margarita y Rosalila. Para el Clásico temprano un caso prototipo es la Estela 31 de Tikal (Figura 13B), que muestra a Siyaj Chan K'awiil con su nombre sobre la cabeza e incorporado a su tocado, como el lugar lógico en el que se colocan elementos que refieren a la identidad social (ver Zender 2014, p. 64).

Regresando a la EIA, el personaje 3 del friso de Balamkú (Figura 13C) presenta dos elementos en su tocado que conforman en parte un nombre-emblema: el ícono del rostro del dios K'inich y un signo de brazos levantados que indica el acto de cargar ${ }^{16}$. Por medio de estos elementos del tocado sabemos que el gobernante se identifica con un aspecto específico del dios solar, como cargador.

15. En el caso del relieve de Margarita, la guacamaya y el quetzal se muestran de cuerpo completo, mientras que en el relieve de Rosalila ambas aves están referidas únicamente por elementos iconográficos diagnósticos fusionados en un solo rostro, en un juego de « la parte por el todo »: el tocado del dios K'inich (al centro), tiene rasgos de quetzal (cresta, color verde) y los ojos de una guacamaya. Una fusión similar se da en el tocado nominal de K'inich Yax K'uk' Mo' en el Altar Q de Copán (ver Figura 13A) y en su nombre en el marcador Motmot (ver Taube 2000, Fig. 22e).

16. No existe una lectura aceptada para este logograma de los brazos levantados en posición de cargar. La interpretación del tocado del personaje 3 del friso de Balamkú como un 

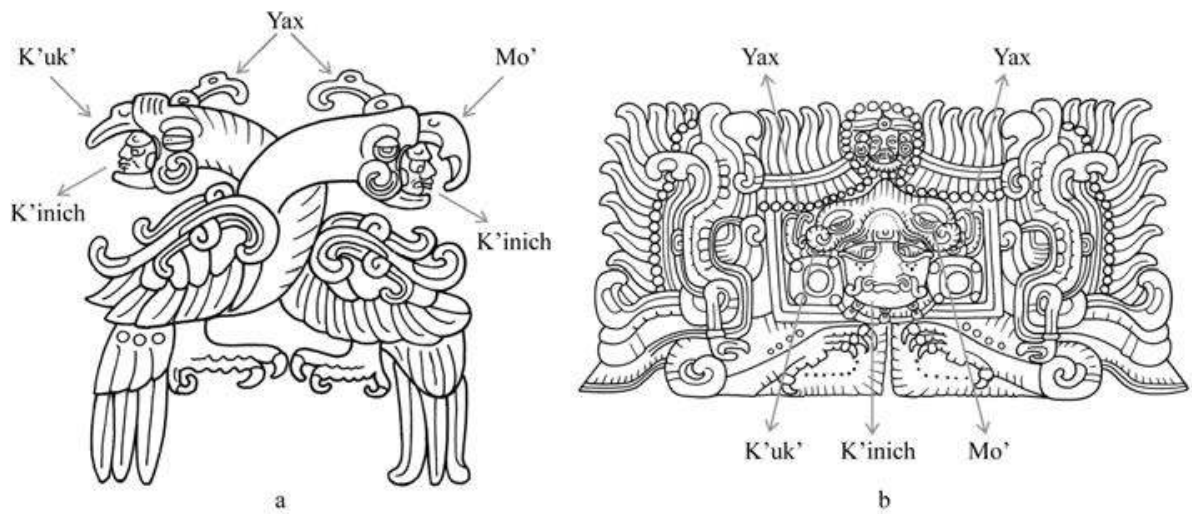

Fig. 12 - a. Relieve de estuco del Edificio Margarita (detalle); basado en levantamiento 3D hecho por A. Tokovinine, en Tokovinine (2013); b. Relieve de estuco del Edificio Rosalila, Copán; basado en dibujo previo de J. Espinoza y J. Ramos, en Argucia Fasquelle y Fash (2005). Dibujos de Daniel Salazar.
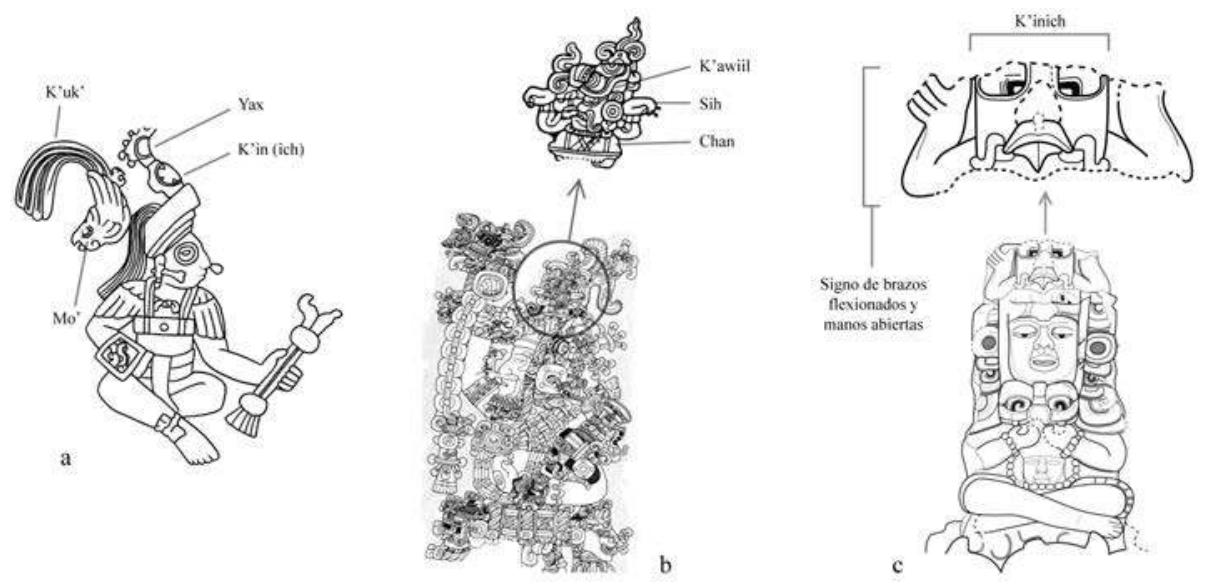

Fig. 13 - a. Retrato de K'inich Yax K'uk' Mo' en el Altar Q de Copán (Clásico tardío); dibujo modificado de Stuart (2004); b. Sihyaj Chan K'awiil en la Estela 31 de Tikal (detalle); dibujo modificado de Hellmuth (1987); c. Tocado del Personaje 3 del friso de Balamkú; dibujo de Daniel Salazar. 
En este sentido, concuerdo con las ideas de Ana García Barrios y colaboradores (2005) acerca del contenido mitológico de algunos nombres de la realeza y su valor connotativo. Simon Martin (2002, p. 59) y Nikolai Grube (2002, p. 324) plantean que para los miembros de la realeza maya fue una práctica frecuente el adquirir rasgos específicos de un dios en particular usando un teónimo como parte de sus nombres personales. Al respecto, y enfocándonos en los relieves mencionados de Copán y en el probable caso del personaje 3 de Balamkú, sigo a Pierre Colas (2003, p. 270-271), quién propone que al incorporar el nombre del dios solar a un antropónimo real, ya sea definiendo un aspecto de la identidad social de los gobernantes o sus cualidades individuales (innatas), se genera una asociación simbólica a través de la cual se adopta parte de la identidad y el poder del dios ${ }^{17}$.

El recurso de usar referencias a dioses como parte de los nombres personales de los gobernantes tiene un equivalente en los nombres-emblemas, que serían maneras de expresar esa misma idea en imágenes, y en estos casos como esculturas integradas en la arquitectura.

\section{Forma 5. La integración de los retratos de gobernantes a un espacio cosmológico/ mítico}

Esta es tal vez la forma más clara de atribuirle una " dimensión cósmica » a la figura real (Baudez 1995, p. 49-50). El espacio puede estar representado como montaña zoomorfa, la tierra solucionada en forma de banda con motivos terrestres, el cielo como el cuerpo de una criatura reptil bicéfala o una banda con signos celestes, o una combinación de dos de estos motivos (Figuras 14A y B). La imagen del gobernante, al centro o en la parte superior de los cosmogramas, se presenta como un eje dentro de la composición, adquiriendo una relevancia acorde con el entorno: las bandas celestes enmarcan su imagen, mientras que las bandas terrestres siempre se encuentran en la parte inferior, como base (Figura 14B); cuando se trata de montañas zoomorfas, los personajes se ubican en las fauces/cueva (Figura 14D), surgiendo a través de una hendidura escalonada en la cabeza de los zoomorfos (Figura 15), o simplemente de pie o sentados sobre la montaña, a manera de trono (Figura 14C).

Una variante de esta forma de representación es mostrar a un antepasado en la parte superior de las composiciones, aludiendo con su naturaleza y su

tocado nominal se basa en la recurrente integración del logograma de los brazos levantados a los nombres de distintos gobernantes y dioses durante el Clásico, y en la larga tradición de colocar los nombres personales sobre la cabeza - como tocados o como parte de los tocados - de los personajes reales. Los orígenes de esta práctica se remontan hasta finales del Preclásico, 100 a.C.-150 d.C. (ver Houston [2004, p. 302]. Para una discusión detallada al respecto del tocado del personaje 3 de Balamkú, consultar Salazar Lama [2014, p. 127-131]).

17. Sobre los usos y funciones del lexema K'inich en los antropónimos reales, consultar Colas (2003). Sobre la asimilación entre el rey maya y el sol, véase en particular Baudez 2006. 

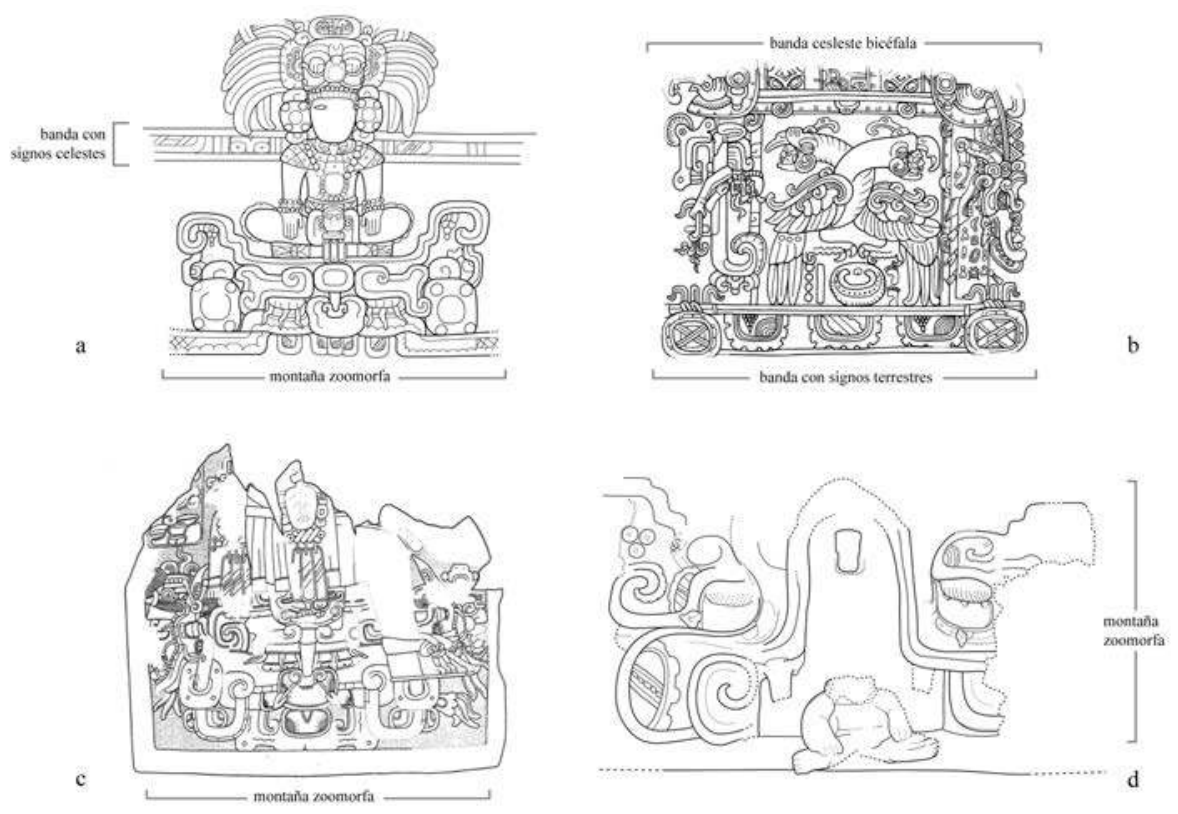

Fig. 14 - a. Personaje central del friso de Holmul; basado en dibujo previo de A. Tokovinine. Cortesía de Francisco Estrada-Belli; b. Relieve de estuco del edificio Margarita; basado en levantamiento 3D hecho por A. Tokovinine, en Tokovinine (2013); c. Detalle del Monumento 106 de Toniná (lápida empotrada en la fachada exterior de la Estructura V). Dibujo tomado de Stuart y Houston (1994); d. Mascarón de la Plataforma 2, Toniná. Dibujos a, b y d de Daniel Salazar.

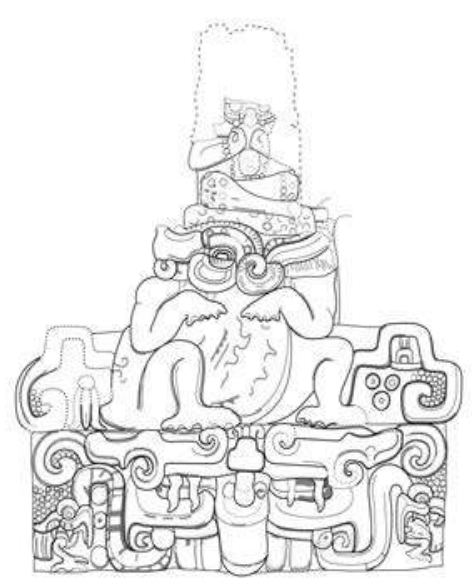

a

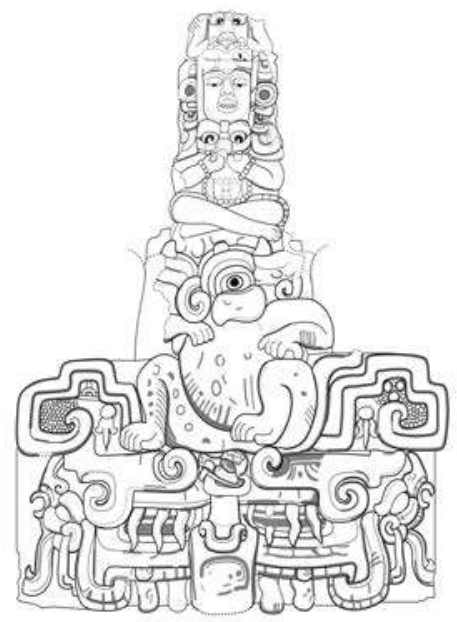

b

Fig. 15 - a y b. Secciones 2 y 3 del friso de Balamkú. Dibujos de Daniel Salazar. 
dimensión cósmica al espacio celestial que ocupa. En las estelas se presentan a esos ancestros como cabezas sin cuerpo flotando sobre las escenas y rodeados de volutas de humo o nubes (ej. Estelas 18 de El Mirador, 31 de Tikal, 2 de Tak'alik Ab'aj y 1 de El Baúl) ${ }^{18}$. Uno de los pocos ejemplos de EIA que muestra esta variante es el friso del edificio H-Sub-2 de Uaxactún, construido a inicios del Clásico temprano (Valdés y Fahsen 2007, p. 1162-1164; Fig. 2).

Las localidades míticas, como las cuatro montañas del friso de Balamkú (ver Figuras $3 \mathrm{~A}$ y 15 ), cuyos topónimos se hallan vinculados a montañas pintadas en los murales de las tumbas 2, 5, 6 y 25 del Clásico temprano en Río Azul (ver Acuña 2007) ${ }^{19}$, y los edificios Corozal (llamado " 9 Imix ») y Ramón (nombrado " 7 jik"? K'an ») en la Acrópolis « Los Arboles » de Xultún (Saturno et al. 2012, p. 568-571) ${ }^{20}$, sirven como un marco espacial y temporal para las acciones y la presencia de los gobernantes. Como lo sugiere Christophe Helmke (2012, p. 92), para el espectador emic la sola mención o la representación de lugares míticos es suficiente para rememorar los episodios allí ocurridos y los agentes involucrados ${ }^{21}$. Así, los gobernantes cobran una relevancia cosmogónica al ser integrados a los paisajes de orden mitológico.

La vinculación de localidades míticas con personajes ancestrales relevantes para el reino sugiere la posibilidad de que estas hayan sido concebidas como lugares de origen dinástico, incorporadas a los discursos de legitimación del

18. Ver imágenes en McAnany (1998, Fig. 5 y 6) y en Valdés y Fahsen (2007, Fig. 3). Para el Clásico tardío, ejemplos de antepasados colocados en la parte superior de las composiciones son las estelas 1, 4, 10, 30 y 33 de Yaxchilán, aunque en estos casos los personajes se presentan dentro de cartuchos solares y solamente algunos sobre bandas celestes.

19. La montaña posiblemente llamada "Sak "Concha" », Concha Blanca, del friso de Balamkú (montaña 2), se halla en los muros norte de las tumbas 2 y 25 , en el muro sur de la Tumba 6 y en el muro oriente de la Tumba 5, todas en Río Azul, Guatemala; la montaña que en el extremo oriental del friso de Balamkú está nombrada con una vasija invertida y el número 9, se encuentra en el muro este de la Tumba 2 de Río Azul; las montañas de los muros oeste de las tumbas 5, 6 y 25 de Río Azul, llamadas Ch'ich Ehb? Witz, Montaña ¿Escalón?-Sangre, y « Ch'ich Ehb? Witz Nal », Lugar de la Montaña ¿Escalón?-Sangre, posiblemente tienen su contraparte en la montaña del extremo oeste del friso de Balamkú. La montaña nombrada con una cabeza de pecarí con un signo K'in (sol) en la frente y una media luna en el friso de Balamkú (montaña 3), se encuentra tallada sobre un fragmento de vasija de madera, probablemente proveniente de la Tumba 1 de Río Azul.

20. « 9 Imix » y « $7 \mathrm{~K}$ 'an » como localidades míticas relacionadas con figuras reales se encuentran en muchos sitios y monumentos del área maya. Dos claros ejemplos son el llamado Marcador Motmot de Copán, donde 9 Imix está asociado a K'inich Yax K'uk Mo' y 7 K'an a su sucesor, y el relieve de estuco del Edificio Margarita, también en Copán, que vincula a la figura del fundador del linaje (K'inich Yax K'uk Mo') de nuevo con 9 Imix (Fash y Fash 1996).

21. En una investigación reciente (2015), Ana García Barrios plantea que para poder reconstruir una narrativa mítica es suficiente contar con un elemento esencial del episodio, el cual funciona como pars pro toto (parte por el todo) y hace referencia al evento completo. En nuestro caso de estudio, y acorde con lo que plantea Helmke (2012), este elemento de la narrativa puede ser una localidad. 


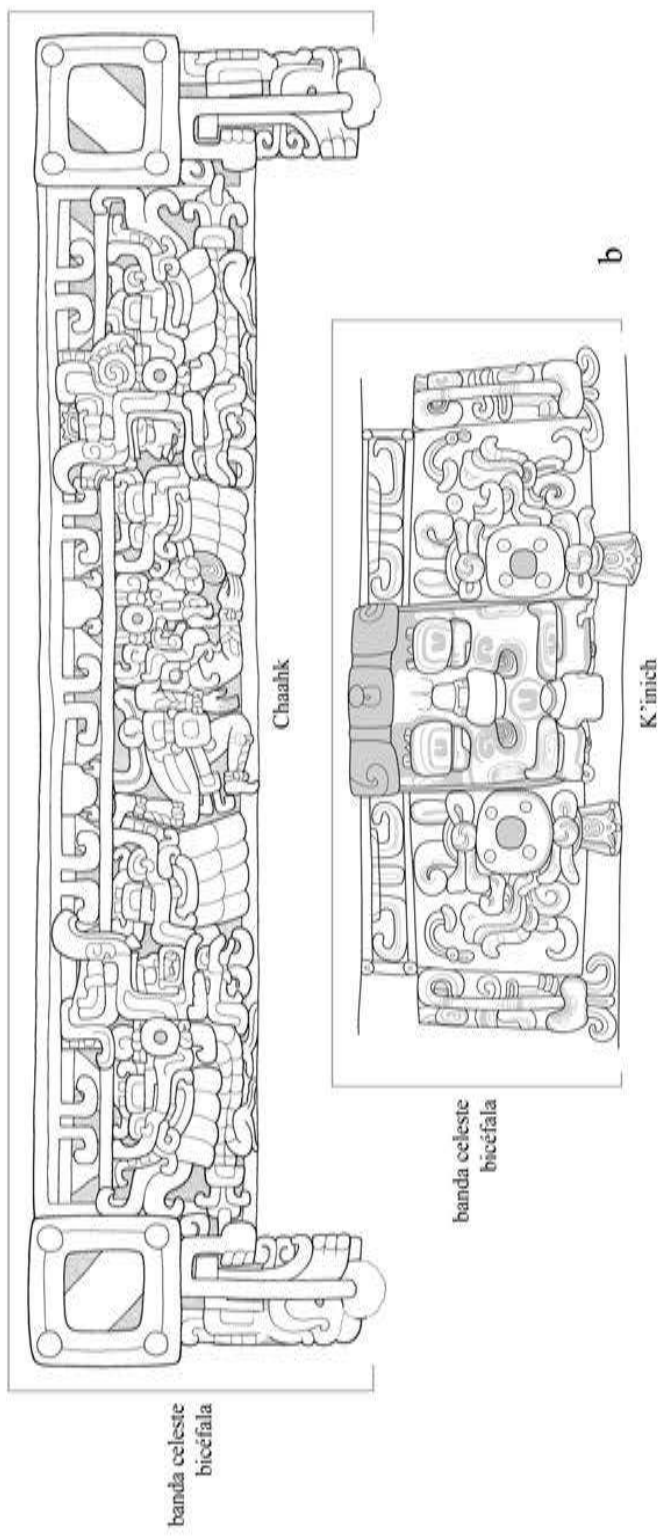

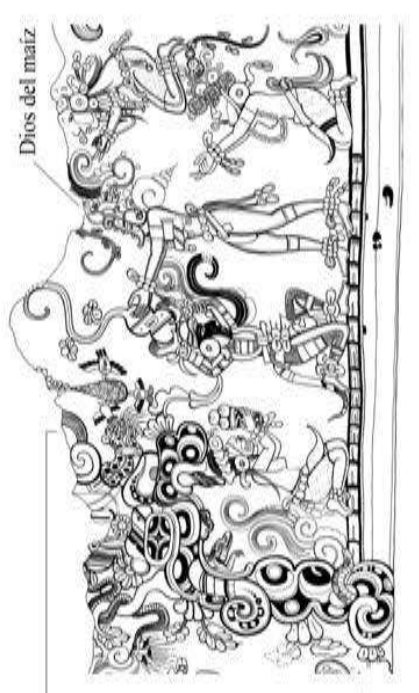

I
율

๓ ฮี 흔 웜

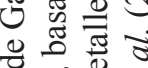

ถีอั

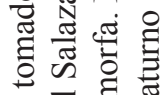
घ. छ ह สี

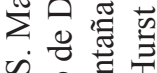
ฯ 을 픔 윽 爷要 蛋的㐘 苛

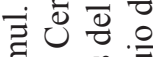

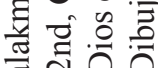
สูก in $: \frac{0}{\circ}$ U 尼

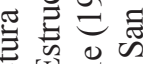
되 잉 E़ी

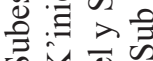

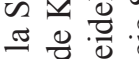
을 윻 ฮ

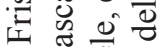

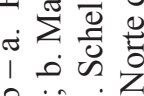
음 i 玒 
poder. Este es el caso de las montañas del friso de Balamkú (Salazar Lama 2014, p. 80-85, 211-216) y de los mascarones del edificio Bayal (Xultún), que incorporan el jeroglífico $\mathrm{Wak} \mathrm{Sa}$ 'aal, asociado a un linaje de relevancia regional y a las acciones de sus posibles fundadores (Saturno et al. 2012, p. 564-568).

En el arte del Preclásico los espacios cosmológicos están definidos con recursos formales e iconográficos en parte similares a los ejemplos del Clásico, pero son ocupados de forma casi exclusiva por deidades (Figuras 1C y E; 16).

\section{Forma 6. La realización de acciones prototípicas de los dioses}

Acorde con el espacio que ocupan, las acciones de los gobernantes representadas en la EIA del Clásico temprano en muchos casos emulan aquellas realizadas por los dioses. Generalmente se muestran antepasados reales surgiendo desde el inframundo, interactuando y formando parte activa de una estructura cosmológica mediante portales o umbrales que comunican los distintos planos del cosmos. Las vías por las que transitan pueden ser las fauces o la hendidura en la frente de las montañas zoomorfas, las bocas abiertas de reptiles y anfibios (Baudez 2005), o el motivo de cuatro lóbulos, elemento iconográfico que en Mesoamérica se vincula recurrentemente a la dimensión cósmica de los gobernantes (Guernsey 2010, p. 90-91).

El friso del Edificio 2 de la Estructura X de Becán (250-450 d.C.) (Figura 17A) presenta a un gobernante emergiendo entre dos montañas zoomorfas, imitando la postura de «contorsionista » con la que a veces se ve al dios del maíz al momento de renacer (Figura 17B; Taube 2005, p. 25-27 y Martin 2006b). En el friso de Becán, el cuerpo del personaje, volteado hacia arriba y ubicado detrás de su cabeza y hombros, toma la forma de un árbol marcado con el motivo de cuatro lóbulos al centro. De esta manera, el gobernante emula el renacimiento del dios del maíz en su función de eje cósmico (Figura 17C).

Quienes realizan estas acciones generalmente se muestran en la culminación de un proceso de transformación iniciado con su muerte, gracias al cual pueden emerger a la superficie terrestre o elevarse al ámbito celeste. Al hacerlo, los personajes reales adquieren las características conductuales de ciertas deidades, incorporándose a los ciclos de muerte y renacimiento de K'inich o del dios del maíz. Estos actos pueden a su vez recrear episodios cosmogónicos - algunos de carácter mítico - realizados por los dioses, como los personajes 2 y 3 del friso de Balamkú, que renacen como el dios del maíz y como un personaje vinculado a K'inich en su papel de cargador (Figuras 16A y B) ${ }^{22}$. Al hacerlo,

22. Estos episodios cosmogónicos son recreados a través de distintos elementos y motivos iconográficos, como las montañas de carácter mítico que contextualizan las acciones, la falda de red del personaje 2 y el tocado nominal del personaje 3 (ver formas 3 y 4 ), y las criaturas zoomorfas de las que ambos gobernantes emergen, lo que indica la acción de resurgir o renacer. Para una discusión detallada consultar Salazar Lama (2014). 

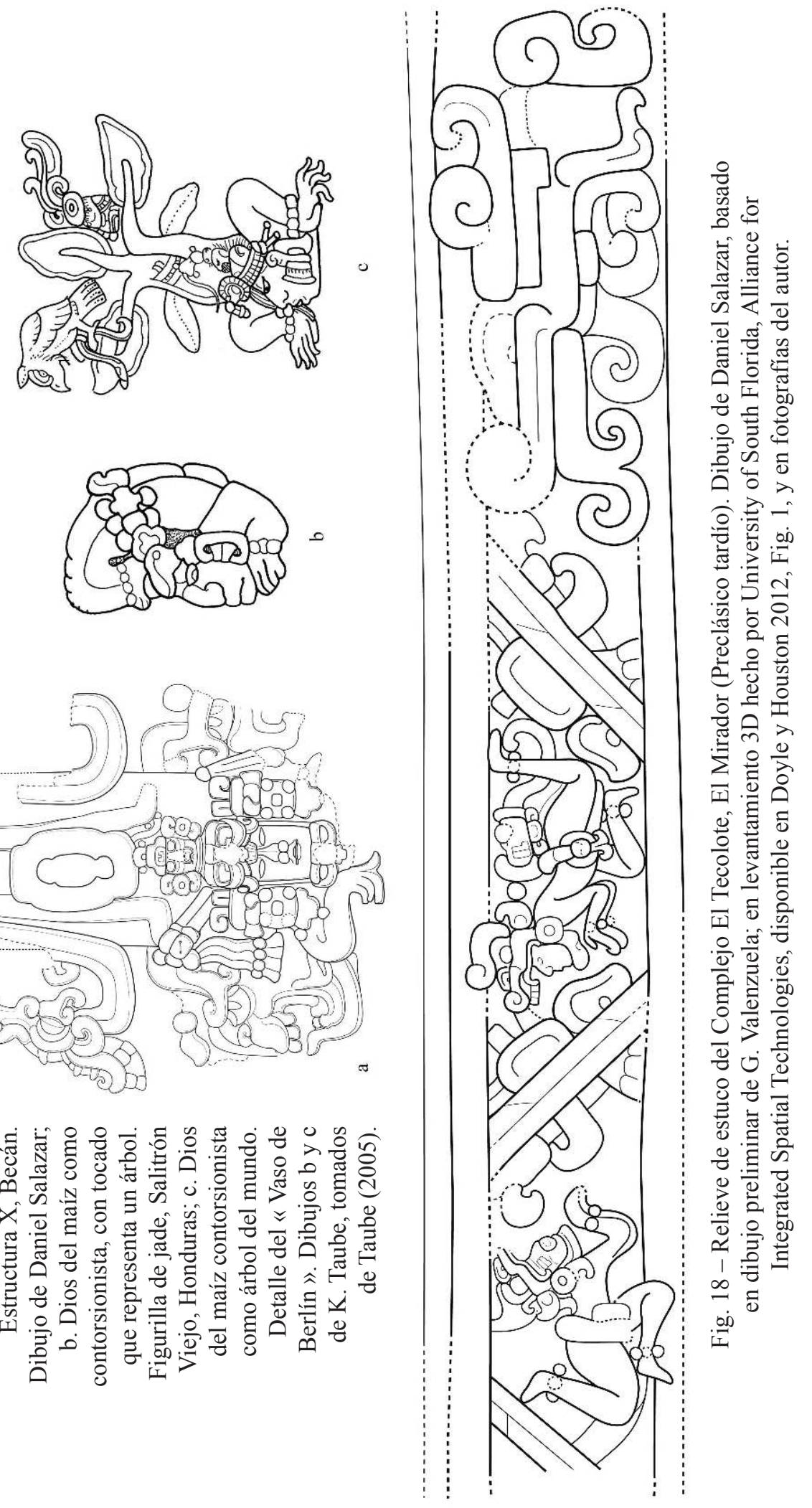

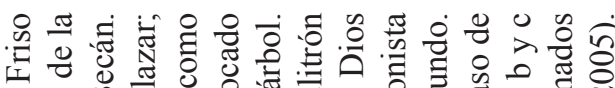
ن $\sim$ ص

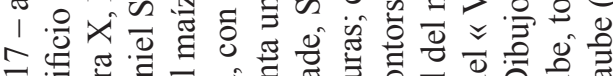

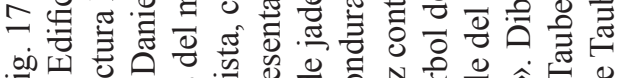

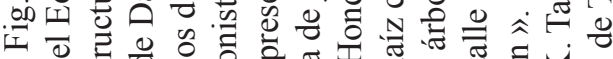

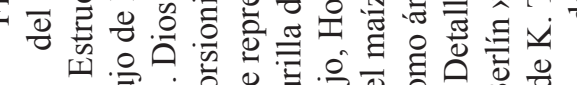

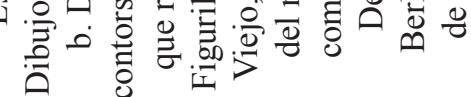


los gobernantes personifican deidades en momentos específicos, adoptando sus funciones cosmogónicas y presentándose como héroes victoriosos que se adjudican el poder de generar y controlar la dinámica y las fuerzas que operan en la naturaleza, estableciendo una metáfora que se extiende a su reinado, como la instauración de un nuevo orden de alcance cósmico (ver Pope 2006, p. 42, 79; García Barrios 2015).

En el Preclásico tardío un único ejemplo de EIA que muestra un evento mítico/cosmogónico protagonizado por un gobernante es el relieve de estuco del complejo El Tecolote, en El Mirador (Figura 18). En él, un personaje real porta la máscara del dios de la lluvia, Chaahk, al descender de una banda celeste (Doyle y Houston 2012). Este episodio se encuentra representado en el friso de la estructura Sub IIC-I de Calakmul, en la Estela 23 de Izapa, y en los mascarones de Bayal (Xultún), con Chaahk como actor principal (consultar García Barrios [2007 y 2009] para un estudio detallado acerca de los ámbitos y espacios de acción del dios).

Forma 7. Mostrar a los gobernantes con la apariencia de una deidad, con sus rasgos y características formales

Esta forma de representación necesita de referencias escritas, iconográficas o contextuales que indiquen la naturaleza de los personajes, para llegar así a una correcta identificación.

Existen dos esculturas en piedra que ayudarán a comprender esta práctica en la EIA (Figuras 19A y B). El primer caso es el retrato de Yax Nuun Ahiin en la Estela 31 de Tikal, donde este rey fallecido se presenta con los rasgos diagnósticos del dios solar - ojos y pupilas cuadradas, tres puntos en la mejilla y apéndice nasal de serpiente de hocico cuadrado -, pero usando un tocado nominal que representa su nombre-emblema, gracias al cual se le puede identificar. Un segundo ejemplo es la imagen de K'inich Janaab' Pakal en su lápida sepulcral, cuyo rostro y cabeza cuentan con ciertos rasgos del dios del maíz y de K'awiil (cabeza alargada con un corte de cabello similar al del dios del maíz y un hacha de jade humeante incrustada en la frente). Gracias a los textos asociados y al contexto particular de la lápida (sobre el sarcófago que aloja los restos de Pakal) se puede asegurar que se trata de la representación del gobernante fallecido. Al adoptar los rasgos fisonómicos de K'inich, del dios del maíz y de K'awiil, Yax Nuun Ahiin y K'inich Janaab' Pakal se fusionan con estos dioses, lo que les permite adquirir sus atributos y capacidades, y ocupar espacios cosmológicos.

En la EIA del Clásico temprano, un ejemplo en parte similar al caso de Yax Nuun Ahiin es el programa escultórico de la Estructura A-1 de Kohunlich (250450 d.C.) (Figura 20, página precedente). Para poder reconocer correctamente los personajes retratados en este conjunto de mascarones es necesario estudiar en detalle todos los elementos iconográficos que conforman sus rostros. Así, 

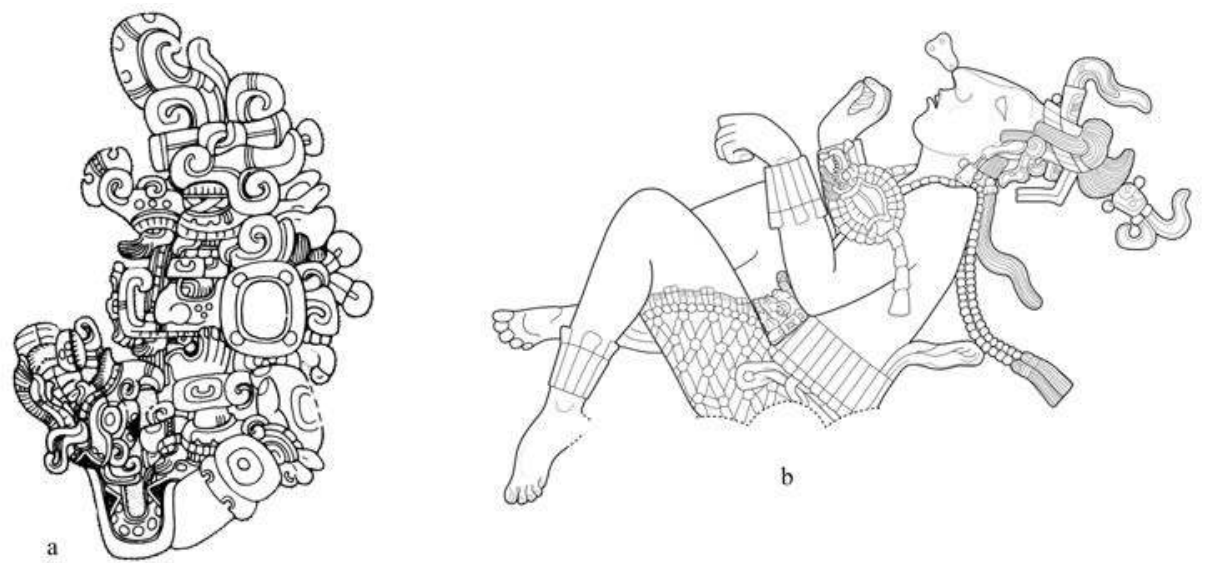

Fig. 19 - a. Yax Nuun Ahiin, detalle de la Estela 31 de Tikal (Clásico temprano). Tomado de Hellmuth (1987); b. Figura de K'inich Janahb' Pakal, detalle de la Lápida del Templo de las Inscripciones, Palenque (Clásico tardío). Dibujo de Daniel Salazar.
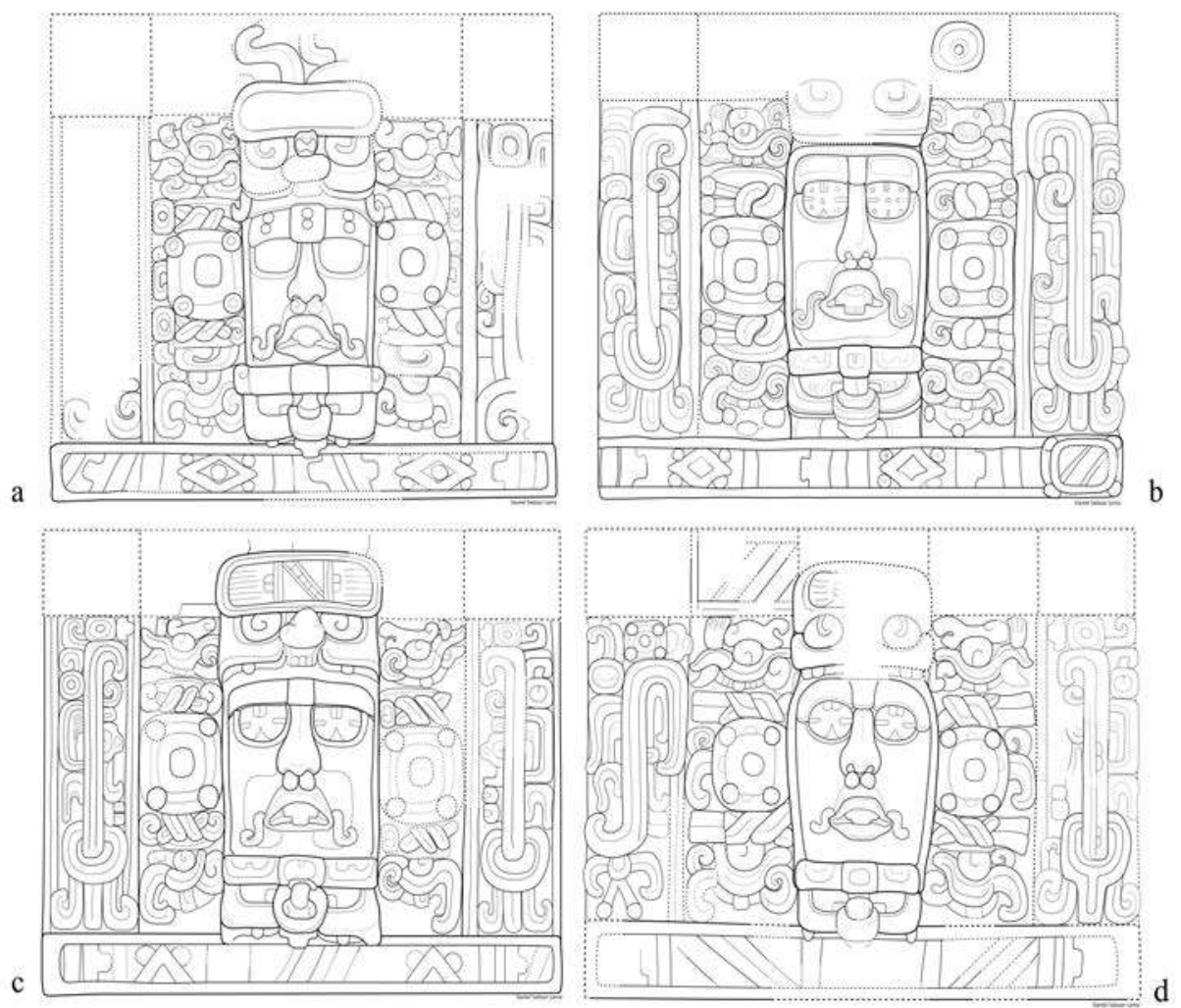

Fig. 20 - Mascarones del segundo y tercer cuerpo de la Estructura A-I de Kohunlich:

a. Tercer cuerpo, lado norte; b. Tercer cuerpo, lado sur; c. Segundo cuerpo, lado norte; d. Segundo cuerpo, lado sur. Todos los dibujos de Daniel Salazar, basados en estudio fotográfico del autor y en modelos 3D de Mássimo Stéfani. 
es posible notar que dentro de los ojos de los mascarones del segundo cuerpo, a pesar de su forma cuadrangular que claramente no es humana, se encuentran a manera de pupilas versiones geométricas del ícono que corresponde al logograma winik, « hombre, persona », (Figuras 20C y D) signo que en este contexto define la naturaleza humana de los individuos retratados ${ }^{23}$. El mascarón del tercer cuerpo, lado norte (Figura 20A), tiene los ojos casi cuadrados - rasgo de $\mathrm{K}$ 'inich - y vacíos, y el personaje porta una especie de casco seccionado en tres « placas », pieza del tocado del dios solar (Figuras 1A y 7B). Por su parte, el mascarón del tercer cuerpo, lado sur (Figura 20B), tiene pupilas que se forman de la conflación de la variante geométrica del signo winik y del signo $k^{\prime}$ in $(\mathrm{sol})^{24}$.

Bajo el esquema aquí analizado, es factible proponer que los personajes retratados en estos mascarones son seres humanos mostrados en pleno proceso de fusión con el dios solar, adquiriendo sus rasgos formales a medida que suben por los cuerpos del basamento piramidal, como una metáfora que indica su ascenso por el horizonte ${ }^{25}$. El contexto arquitectónico es crucial para

23. Además de traducirse como «persona, hombre », el logograma WINIK sirve también para designar un período de 20 días. No considero que en el contexto de los mascarones este signo tenga una función calendárica.

Es necesario aclarar que en ningún otro contexto iconográfico (por lo menos que yo conozca) los ojos de personajes humanos o de gobernantes fueron utilizados de esta manera, como nichos para colocar signos escriturarios o algún tipo de recurso gráfico que hiciera referencia a la « humanidad» del individuo retratado. Sin embargo, es interesante constatar que en otros casos, como algunos dioses y demás seres sobrenaturales, los ojos muchas veces definen y aluden a la naturaleza y la esencia de los personajes. Cabría pensar, por lo tanto, que dentro del rostro, las características formales de los ojos corresponden con la identidad y la naturaleza de los individuos y los dioses. Así, los ojos de los seres vinculados con los reptiles y los ámbitos acuáticos o del inframundo tienen por lo general pupilas enroscadas dentro de ojos circulares (véanse por ejemplo los ojos de GI, K'awiil y GIII; consultar Houston y Taube 2000, p. 281-287); mientras que los seres celestes, especialmente el dios solar K'inich y la Deidad Ave Principal, tienen pupilas angulares y esquinadas, dentro de ojos rectangulares y grandes. El ejemplo de los mascarones de Kohunlich es excepcional; en mi opinión, en estos retratos los ojos fueron utilizados por el artista como espacios para colocar, de la misma forma que en las imágenes de los dioses mencionados, signos (utilizados como elementos iconográficos) que hacen referencia a la naturaleza de los personajes, con la finalidad de facilitar su identificación. Si se atiende a las convenciones iconográficas propias de los dioses, ninguna imagen de la deidad solar presenta ojos con las características vistas en los mascarones de Kohunlich.

24. Una variante de la forma cuadrilobular del signo $k$ 'in es la que incluye puntos o pequeños círculos en el centro de cada lóbulo o pétalo; algunos casos, como la banda celeste que enmarca la escena en la lápida de K'inich Janahb' Pakal en el Templo de las Inscripciones, cada pétalo posee una hilera de puntos y uno grande al centro de la forma cuatrilobular. En el caso de los ojos del mascarón del tercer cuerpo sur de la Est. A-1 de Kohunlich, estos círculos (uno central y uno en cada lóbulo) son los elementos diagnósticos del signo $k$ 'in, fusionado con el signo winik; a su vez, la forma de cuatro lódulos del signo winik permite que el signo $k$ 'in fusionado guarde su configuración original.

25. Los mascarones se encuentran en la fachada oeste; sin embargo, el espectador de pie frente a la fachada principal del edificio, ve desplegado el programa escultórico hacia el oriente. 
sustentar esta interpretación. La Estructura A-1 es un basamento piramidal de cuatro cuerpos escalonados con un templo de cinco crujías en su parte superior; dentro del templo se encontró un espacio sepulcral de élite debajo del piso de uno de los cuartos posteriores (Segovia Pinto 1981, p. 224) ${ }^{26}$. Teniendo este detalle en cuenta y estudiando el comportamiento de la EIA de los recintos de veneración a los antepasados reales (ver McAnany 1995 y 1998; Taube 2004), es posible sugerir que los mascarones de la fachada oeste del edificio representan al personaje sepultado en el adoratorio que corona la estructura, mostrado en un episodio de concurrencia entre un ente divino y un agente humano, es decir, fusionado con $\mathrm{K}$ 'inich en el instante de elevarse por el este, imitando las características conductuales del $\operatorname{dios}^{27}$.

\section{Discusión: implicaciones ideológicas del patrón de representación}

El mensaje de una obra, entendido como su trasfondo o sentido profundo, conformado por argumentos y contenidos de significación que cobran valor dentro de contextos sociales e históricos específicos, es el objeto del proceso comunicativo, proceso que a su vez es la función primaria de todo objeto artístico (Preziosi 1989, Cap. II y IV; Sanz Castro 1998b, p. 73).

La EIA de las tierras bajas mayas enfocada en la imagen de gobernantes y antepasados logra expresar una conexión funcional entre la figura real y el ámbito de lo sagrado, colocando su presencia y su persona en contacto directo con asuntos sobrenaturales que escapan a la mayoría de la población.

Teniendo en cuenta estos factores, se puede definir el mensaje de la EIA del Clásico temprano como la proclamación de la dimensión sagrada del oficio real, así como la majestuosidad y sacralidad de la persona del gobernante y su linaje a través de sus múltiples vínculos con los dioses, con las fuerzas que dinamizan y ordenan el cosmos y con los ciclos naturales de existencia.

¿Qué papel juega este mensaje dentro del aparato ideológico de los mayas del Clásico temprano? Para entenderlo, se debe primero puntualizar qué se entenderá por ideología. En este trabajo, se definirá como un sistema de ideas compartidas por toda una sociedad, que es manipulado por ciertos sectores

26. La tumba, que fue saqueada durante la década de 1960, aún contenía parte del mobiliario funerario cuando fue explorada por los arqueólogos, como teselas de piedra verde, huesos y conchas talladas y artefactos de cerámica (Segovia Pinto 1981, p. 219, 282). Estos materiales y el contexto arquitectónico son claros indicadores del estatus social del individuo.

27. En concordancia con esta idea, los rostros de los personajes están enmarcados por bandas celestes bicéfalas, como marcadores espaciales que indican su ubicación en el cielo del oriente. Marta Foncerrada de Molina (1983, p. 12) esboza brevemente una interpretación parecida, y plantea « [...] la posibilidad de considerar a las cabezas [mascarones de Kohunlich] como monumentos funerarios realizados para conmemorar la vida de uno o varios dignatarios. La imagen repetida significaría la actualización revitalizadora del gobernante divinizado dentro de la comunidad ». 
elitistas con el propósito de legitimar su acceso al poder y justificar el ejercicio del poder. De acuerdo con López Austin (1976, p. 197), « en Mesoamérica la ideología tenía su apoyo más sólido en el complejo que integraban la cosmovisión, la religión y la magia ».

La idea y la experiencia de lo sagrado, fincado en el complejo cosmovisión/ religión/magia mencionado por López Austin, traspasa sus límites y nutre al aparato ideológico manejado por las élites y la realeza, el cual es utilizado para hacer visibles las divisiones que operan en el mundo, reflejadas en la jerarquización y el funcionamiento de la sociedad (Bourdieu 1989); es decir, las sentencias y los estatutos concernientes a lo económico, a la autoridad y a otras convenciones sociales son por lo general sacralizadas.

Basándose en Gregory Bateson (1951), Roy Rappaport (1971, p. 30) sugiere que los mensajes de carácter sagrado son fácilmente aceptados por la población en general. Al respecto, concuerdo con lo planteado por García Capistrán (2013) acerca de la dimensión sagrada de los gobernantes mayas, de su linaje y de su oficio real; dimensión que al estar construida a partir de creencias religiosas y formas de concebir el mundo compartidas por la población se convierte en un poderoso instrumento político.

Hacia los inicios del Clásico temprano, después del declive de algunos de los grandes reinos mayas del Preclásico como Nakbé, El Mirador, Cival o Tintal, alrededor de los siglos II y III d.C., nuevos reyes y nuevas dinastías aparecen en nuevos lugares, trayendo consigo novedosas expresiones artísticas de corte más individualista (Estrada-Belli 2011, p. 117-122), como las estelas y la EIA, que invaden el espacio público. Aunado a este fenómeno, pero de aparición más tardía ${ }^{28}$, hacia mediados del Clásico temprano, el título $K$ 'uhul Ajaw, « Señor Sagrado », comienza a ser utilizado por los gobernantes de las grandes ciudades de la época. Convertido en un recurso para declarar el cargo y el estatus de los señores supremos, este título también fue una herramienta para definir a los soberanos como encarnaciones de lo sagrado. Existe tanto en la lengua hablada y escrita como en la imagen de los monumentos públicos una insistencia simbólica cuyo significado remite a la dimensión y la concepción de la figura real.

Estas prácticas se suman a la proliferación gradual de enterramientos de gobernantes en edificios públicos a partir del 200-250 d.C. (Laporte 2005), muchos de los cuales se convierten en los ejes que dictan las pautas del crecimiento, el ordenamiento y el simbolismo del entorno, constituidos como lugares de veneración. En conjunto, estas evidencias (el cambio temático de la EIA, la aparición de las estelas, el título K’uhul Ajaw y los lugares de culto que

28. Las investigaciones recientes del Proyecto Petén Norte-Naachtun han documentado el título K'uhul Ajaw en la Estela 24 de Naachtun, fechada para la segunda mitad del siglo IV (Lacadena y Cases 2014). 
albergan a los soberanos fallecidos) son manifestaciones culturales del papel predominante del ajaw en la sociedad y de los conceptos que progresivamente se aglutinan a su alrededor.

De forma concreta, los cambios detectados en la EIA son indicadores de la creciente necesidad de los nuevos gobernantes por incrementar y consolidar su poder. La sacralización de su imagen, su persona, su linaje y su oficio resultan de la búsqueda de una estabilidad política y la legitimación del acceso al poder frente a la población y a otros grupos de élite contendientes. Así, la integración del retrato monumental de estos personajes emblemáticos al espacio público (forma de representación $\mathrm{N}^{\circ} 1$ ), es uno de los mecanismos a través de los cuales la institución real encuentra una plataforma física ideal para la transmisión de mensajes de esta naturaleza. Como lo sugiere Takeshi Inomata (2006, p. 805), « La experiencia y la percepción subjetiva de la población acerca de la autoridad y de la unidad social fueron cuidadosamente tejidas y acentuadas en contextos espaciales y temporales específicos, a través de eventos y proyectos constructivos patrocinados por el estado y las élites. »

\section{Conclusión}

Like language however, iconography conveys conventional or agreed meanings. [...] some iconographies are in part accessible to everyone, by being visible, repetitious, and consistent. George Kubler (1969, p. 48).

La consistencia y la repetitividad de elementos iconográficos en torno a la imagen de los gobernantes nos han permitido reconocer un patrón de representación difundido en las tierras bajas mayas a partir de los inicios del Clásico temprano.

Durante el Clásico tardío, los nuevos soportes escultóricos, como las columnas, los taludes de plataformas monumentales y las fachadas con relieves en mosaico, se enfocan en una gran variedad de temas y seres. Gradualmente los mascarones caen en un parcial desuso; sin embargo, los frisos y cresterías descubiertos a la fecha siguen los lineamientos formales y un patrón de representación similares a los del Clásico temprano, como la crestería del Templo del Sol en Palenque (Figura 21, página siguiente).

Para el Preclásico tardío, la escultura pública de Izapa, Tak'alik Ab’aj, Kamilnaljuyú y del occidente salvadoreño, ya mostraba a los gobernantes locales vinculados con los dioses, los pasajes míticos y los espacios cosmológicos ${ }^{29}$. Sugiero que la conformación y el desarrollo del patrón de representación en la EIA del Clásico temprano, su función y su mensaje, pudieron haber tomado como modelo, además de los programas escultóricos monumentales del Preclásico

29. Ver Guernsey (2006, 2010); Henderson (2010, 2013); Paredes Umaña y Salazar Lama (en prensa), entre otros. 


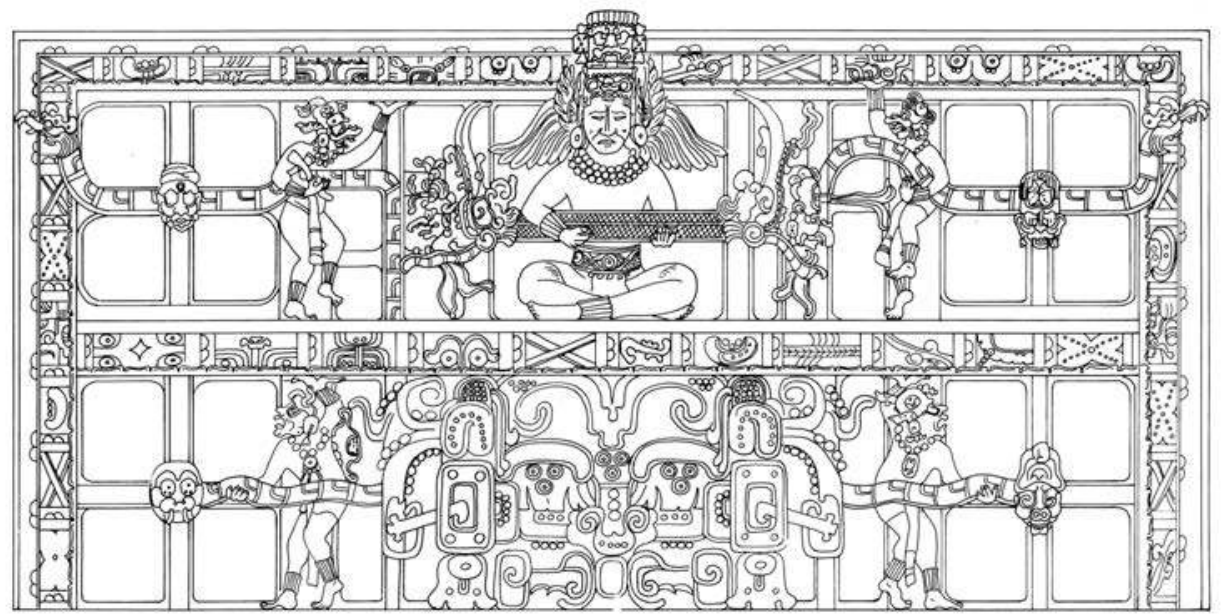

Fig. 21 - Crestería del Templo del Sol, Palenque. Dibujo reconstructivo de M. G. Robertson. Tomado de Greene Robertson (1991).

en las tierras bajas centrales, algunas de las piezas de la tradición escultórica de estos sitios de la costa del Pacífico.

A través del análisis de la EIA del Clásico temprano y del reconocimiento y estudio de su patrón de representación, se intentó mostrar que la exaltación y la glorificación de la figura real en las tierras bajas mayas encuentran uno de sus puntos culminantes en estos programas escultóricos, mismos que apuntan, junto con las evidencias epigráficas y la relevancia del ajaw dentro del entorno, a un cambio del paradigma en la concepción de la realeza y la persona del gobernante, posiblemente como una respuesta a las necesidades sociales y políticas de la época. *

* Manuscrit reçu en septembre 2013, accepté pour publication en avril 2015.

Agradezco principalmente a Dominique Michelet por alentarme a escribir este texto a partir de la ponencia presentada en el IX Congreso Internacional de Mayistas, en la ciudad de Campeche, México; así como por sus comentarios y sugerencias. Reconozco también la enorme ayuda y los consejos de Luz Evelia Campaña, Ana García Barrios, Rogelio Valencia Rivera y Hugo García Capistrán; a todos ellos y a los dictaminadores anónimos de este artículo, gracias por ayudarme a perfeccionarlo. Agradezco a Francisco Estrada-Belli por compartir las fotografías y los dibujos del friso de Holmul, así como a Alexandre Tokovinine por su dibujo del mascarón de la Estructura B-1, también de Holmul.

\section{Referencias citadas}

AcuÑa Mary Jane

2007, Ancient Maya cosmological landscapes: early Classic mural painting at Río Azul, Peten, Guatemala, tesis de maestría, University of Texas, Austin. 
Agurcia Fasquelle Ricardo y Barbara W. Fash

2005, « The evolution of Structure 10L-16, heart of the Copán acropolis », in E. Wyllys Andrew y William L. Fash (eds.), Copán. The history of an Ancient Maya kingdom, School of American Research Press, Santa Fe/James Currey, Oxford, p. 201-237.

BARDAWIL Lawrence

1976, « The principal bird deity in Maya art. An iconographic study of form and meaning », in Merle Greene Robertson (ed.), The art, iconography and dynastic history of Palenque. Part III. Proceedings of the Segunda mesa redonda de Palenque, December 14-21, 1974, Palenque, Pre-Columbian Art Research, Pebble Beach, p. 195-209.

BAssie-SweEt Karen

2002, « Corn deities and the complementary male/female principle », in Vera Tiesler, Rafael Cobos y Merle Greene Robertson (coord.), La organización social entre los mayas. Memoria de la Tercera mesa redonda de Palenque, Conaculta/Inah, México/Universidad Autónoma de Yucatán, Mérida, p. 105-126.

BATESON Gregory

1951, « Conventions of communication: where validity depends upon belief », in Jurgen Ruesch y Gregory Bateson, Communication: the social matrix of society, W.W. Morton, Nueva York, p. 212-227.

BAUDEZ Claude-Francois

1995, «El espacio mítico del rey maya en el período Clásico », Trace, 28, p. 29-52.

2005, « En las fauces del monstruo », Arqueología mexicana, 71, p. 58-67.

2006, « De l'aurore à la nuit : le parcours du roi-soleil maya », Journal de la société des américanistes, 92-1 et 2, p. 41-67.

BENSON Elizabeth P.

1974, « Gestures and offerings », in Merle Greene Robertson (ed.), Primera mesa redonda de Palenque. Part I. A conference on the art, iconography, and dynastic history of Palenque, Pre-Columbian Art Research, Pebble Beach, p. 109-120.

BOURDIEU Pierre

1989, « Social space and symbolic power », Sociological theory, 7 (1), p. 14-25.

Burgos Villanueva Rafael, Yoly Palomo Carillo y Guillermo Kantún Rivera

2013, « Un mascarón de estuco en la estructura Kabul Izamal, Yuc: representación de un personaje mítico o histórico? », in Los investigadores de la cultura maya 21, Universidad Autónoma de Campeche, Campeche, t. I, p. 209-224.

CARrasco Michael D.

2005, The mask flange iconographic complex: the art, ritual, and history of a Maya sacred image, tesis doctoral, University of Texas, Austin.

Clancy Flora

1994, « The Classic Maya ceremonial bar », Anales del Instituto de investigaciones estéticas, 65, p. 7-45. 
Colas Pierre

2003, « K'inich and king. Naming self and person among Classic Maya rulers », Ancient Mesoamerica, 14, p. 269-283.

Doyle James y Stephen Houston

2012, « A watery tableau at El Mirador, Guatemala », Maya decipherment, 9 de abril de 2012, https://decipherment.wordpress.com/2012/04/09/a-watery-tableau-atel-mirador-guatemala/, consultado en junio de 2015.

EstradA-Belli Francisco

2006, « Lightning sky, rain, and the maize god. The ideology of Preclassic Maya rulers at Cival, Peten, Guatemala », Ancient Mesoamerica, 17, p. 57-78.

2011, The first Maya civilization: ritual and power before the Classic period, Routledge, Nueva York.

FASH William y Barbara FASH

1996, « Building a world-view. Visual communication in Classic Maya architecture », RES: anthropology and aesthetics, 29/30, p. 127-147.

Fields Virginia y Dorie ReEnTs-Dubet (eds.)

2005, Los mayas. Señores de la creación. Los orígenes de la realeza sagrada, Editorial Nerea, Donostia.

Foncerrada De Molina Marta

1983, « La exaltación del gobernante maya », Anales del Instituto de investigaciones estéticas, 53, p. 7-29.

FreIDEl David y Linda Schele

1988a, « Symbol and power: a history of the lowland Maya cosmogram », in Elizabeth P. Benson y Gillett G. Griffin (eds.), Maya iconography, Princeton University Press, Princeton, p. 44-93.

1988b, « Kingship in the late Preclassic Maya Lowlands: the instruments and places of ritual power », American anthropologist, 90, p. 547-567.

GARcía BARrios Ana

2007, «El dios Chaahk en el Preclásico maya », in Los investigadores de la cultura maya 15, Universidad Autónoma de Campeche, México, t. 1, p. 267-278.

2009, Chaahk, el dios de la lluvia, en el periodo Clásico maya: aspectos religiosos y políticos, tesis doctoral, Departamento de Historia de América II, Facultad de Geografía e Historia, Universidad Complutense de Madrid.

2015, « El mito del diluvio en las ceremonias de entronización de los gobernantes mayas. Agentes responsables de la decapitación del saurio y nuevas fundaciones », Estudios de cultura maya, 45, p. 9-48.

García Barrios Ana, Ana Martín Díaz y Pilar Asensio Ramos

2005, « Los nombres reales del Clásico: lectura e interpretación mitológica », in Juan Pedro Laporte, Bárbara Arroyo y Hecto Mejía (eds.), XVIII Simposio de investigaciones arqueológicas en Guatemala, 2004. Vol. 2, Ministerio de Cultura y Deportes/Instituto de Antropología e Historia/Asociación Tikal/Foundation for the Advacement of Mesoamerican Studies. Inc., Guatemala, p. 657-666. 
García Barrios Ana y Verónica VÁsquez López

2012, " Moda y protocolo femenino en el reino de Kaanu'l (siglo vil d.C.) », in Philippe Nondédéo y Alain Breton (eds.), Maya daily lives. Proceedings of the 13th European Maya conference (Paris, December 5-6, 2008), Verlag Anton Saurwein (Acta Mesoamericana, 24), Markt Schwaben, p. 95-116.

García Capistrán Hugo

2013, El origen del K'uhul ajaw o de cómo se hicieron sagrados los señores mayas, ponencia presentada en el IX Congreso Internacional de Mayistas, junio de 2013, Campeche.

Grube Nikolai

2002, « Onomástica de los gobernantes mayas », in Vera Tiesler, Rafael Cobos y Merle Greene Robertson (coord.), La organización social entre los mayas. Memoria de la Tercera mesa redonda de Palenque, Conaculta/Inah, México/Universidad Autónoma de Yucatán, Mérida, p. 322-353.

Guernsey K. Julia

2006, Ritual and power in stone. The performance of rulership in Mesoamerican Izapan style art, University of Texas Press, Austin.

2010, " A consideration of the Quatrefoil motif in Preclassic Mesoamerica », RES: anthropology and aesthetics, 57/58, p. 75-96.

HANSEN Richard D.

1992, The archeology of ideology. A study of Maya Preclassic architectural sculpture at Nakbe, Peten, Guatemala, doctoral dissertation, University of California, Los Angeles.

1998, « Continuity and disjunction: the Pre-Classic antecedents of Classic Maya architecture ", in Stephen D. Houston (ed.), Function and meaning in Classic Maya architecture. A symposium at Dumbarton Oaks, 7th and 8th October 1994, Dumbarton Oaks Research Library and Collection, Washington p. 49-122.

Hellmuth Nicholas

1987, Monster und Menschen in der Maya Kunst, Akademische Druck, Graz.

Helmke Christophe

2012, " Mythological emblem glyphs of ancient Maya kings », Contributions in New World archeology, 3, p. 91-126.

HENDERSON Lucia

2010, « La lluvia de los reyes: agua y la iconografía de poder en el sitio Kaminaljuyu », in Bárbara Arroyo, Adriana Linares Palma, Lorena Paiz Aragón y Ana Lucía Arroyave (eds.), XXIII Simposio de investigaciones arqueológicas en Guatemala, 2009, Ministerio de Cultura y Deportes/Instituto de Antropología e Historia/ Asociación Tikal, Guatemala, p. 877-891.

2013, Bodies politic, bodies in stone. Imagery of the human and the divine in the sculpture of late Preclassic Kaminaljuyú, Guatemala, tesis doctoral, University of Texas, Austin. 
Houston Stephen D.

2004, « Writing in early Mesoamerica », in Stephen D. Houston (ed.), The first writing. Script invention as history and process, Cambridge University Press, Cambridge, p. 274-309.

Houston Stephen D., Edwin Roman, Thomas Garrison

2012, «El programa de mascarones de estuco modelado del grupo El Diablo, El Zotz, Petén, Guatemala », in José Luis Garrido López, Thomas Garrison y Edwin Román (eds.), Proyecto arqueológico El Zotz. Informe no. 7, temporada 2012, informe entregado al Instituto de Antropología e Historia de Guatemala, Guatemala, p. 117-121.

Houston Stephen D. y David STUART

1996, « Of gods, glyphs and kings: divinity and rulership among the Classic Maya », Antiquity, 70, p. 289-312.

1998, «The Ancient Maya self: personhood and portraiture in the Classic period », RES: anthropology and aesthetics, 33, Pre-Columbian States of being, p. 73-101.

Houston Stephen D., David Stuart y Karl Taube

2006, The memory of bones. Body, being, and experience among the Classic Maya, University of Texas Press, Austin.

Houston Stephen D. y Karl TAube

2000, «An archeology of the senses: perception and cultural expression in Ancient Mesoamerica », Cambridge archeological journal, 10 (2), p. 261-294.

INOMATA Takeshi

2006, « Plazas, performers, and spectators. Political theaters of the Classic Maya », Current anthropology, 47 (5), p. 805-820.

Knub Julie Nehammer, Simone Thun Y Christophe Helmke

2009, « The divine rite of kings: an analysis of Classic Maya impersonation statements », in Geneviève Le Fort, Raphaël Gardiol, Sebastian Matteo y Christophe Helmke (eds.), The Maya and their sacred narratives. Text and context in Maya mythologies, Verlag Anton Saurwein (Acta Mesoamericana, 20), Markt Schwaben, p. 177-195.

KuBLER George

1969, Studies in Classic Maya iconography, Connecticut Academy of Arts \& Sciences (Memoirs of the Connecticut Academy of Arts and Sciences, 18), New Haven.

LACADENA Alfonso e Ignacio CASES

2014, « Nuevas investigaciones epigráficas en Naachtún, Petén, Guatemala », conferencia dictada el $1^{\circ}$ de octubre en la Coordinación de Humanidades, Unam, México.

LAPORTE Juan Pedro

2005, « La tradición funeraria prehispánica en la región de Petén, Guatemala: una visión desde Tikal y otras ciudades », in Andrés Ciudad Ruiz, Mario Humberto Ruz y Maria Josefa Iglesias Ponce de León (eds.), Antropología de la eternidad. La muerte en la cultura maya, Sociedad Española de Estudios Mayas, Madrid/UnAm, México, p. 49-76. 


\section{LE ForT Geneviève}

1995, Lady Alligator Foot emerges from the past. Maize god iconography at Yomop, Editions de la Galerie Mermoz, París.

[sf], Sacred versus divine. Comments on Classic Maya kingship, texto en posesión del autor.

LóPEz Austin Alfredo

1976, « Fundamento mágico-religioso del poder », Estudios de cultura nahuatl, 12, p. 197-240.

2000, Tamoanchan y Tlalocan, Fondo de Cultura Económica, México [1994].

2006, Los mitos del tlacuache. Caminos de la mitología mesoamericana, Instituto de Investigaciones Antropológicas, UnAM, México [1990].

2012, Cuerpo humano e ideología. Las concepciones de los antiguos nahuas, Instituto de Investigaciones Antropológicas, UnAM, México.

López Austin Alfredo y Leonardo LóPEz LujÁN

2009, Monte Sagrado-Templo Mayor, Instituto Nacional de Antropología e Historia/ Instituto de Investigaciones Antropológicas, UnAm, México.

MARTIN Simon

2002, " The baby jaguar: an exploration of its identity and origins in Maya art and writing ", in Vera Tiesler, Rafael Cobos y Merle Greene Robertson (coord.), La organización social entre los mayas. Memoria de la Tercera mesa redonda de Palenque, Instituto Nacional de Antropología e Historia, ConACulta, México/ Universidad Autónoma de Yucatán, Mérida, p. 50-78.

2006a, The old man of the Maya universe. Towards an understanding of god N, documento presentado en «30th Maya meetings », 14-19 de marzo de 2006, University of Texas, Austin.

2006b, « Cacao in Ancient Maya religion. First fruit from the maize tree and other tales from the underworld », in Cameron L. McNeil (ed.), Chocolate in Mesoamerica. A cultural history of cacao, University Press of Florida, Gainesville, p. 154-183.

MARTIN Simon y Nikolai Grube

2002, Crónica de los reyes y reinas mayas: la primera historia de las dinastías mayas, Crítica, Barcelona.

McAnany Patricia A.

1995, Living with the ancestors. Kinship and kingship in Ancient Maya society, University of Texas Press, Austin.

1998, « Ancestors and the Classic Maya built environment », in Stephen D. Houston (ed.), Function and meaning in Classic Maya architecture. A symposium at Dumbarton Oaks, 7th and 8th October 1994, Dumbarton Oaks Research Library and Collection, Washington, p. 271-198.

Nielsen Jesper y Christophe HelmKe

(En prensa), « La Caída del Gran Ave Celestial: un mito cosmogónico del Clásico temprano en el México central », a aparecer como capítulo en Nikolai Grube y Ingrid Kummelsa (eds.), Teotihuacan: medios de comunicación y poder en la Ciudad de los dioses. 
Paredes Umaña Federico y Daniel Salazar Lama

(En prensa), «Teosíntesis mesoamericana en una tradición escultórica del occidente de El Salvador ».

Pope Elizabeth I.

2006, Mythic architecture and drama in Ancient Mesomaerica: the manifestation of the mythological landscape in the historical world, tesis doctoral, University of Texas, Austin.

Presiozi Donald

1989, Rethinking art history. Meditations on a coy science, Yale University Press, New Haven.

Proskouriakoff Tatiana

1950, A study of Classic Maya sculpture, Carnegie Inst. (Carnegie Institution of Washington, 593), Washington.

2002, An album of Maya architecture, Dover, Nueva York.

QUENON Michel y Geneviève Le FORT

1997, « Rebirth and resurrection in maize god iconography », in Barbara Kerr y Justin Kerr (eds.), The Maya vase book. 5. A corpus of rollout photographs of Maya vase, Kerr Associates, Nueva York, p. 884-902.

RAPPAPORT ROy

1971, « The sacred in human evolution », Annual review of ecology and systematics, 2, p. 23-44.

RoBERTSOn Merle Greene

1991, The sculpture of Palenque, vol. 6, The Cross Group, the North Group, the Olvidado, and other pieces, Princeton University Press, Princeton.

Salazar Lama Daniel

2014, Montañas, antepasados y escenas de resurrección en el friso de Balamkú, Campeche, Tesis de Maestría en Estudios Mesoamericanos, Unam, México.

SAnz CAStro Luis

1997, « Análisis iconográfico de la escultura arquitectónica del Mundo Perdido, Tikal: períodos Preclásico tardío y Clásico temprano », Estudios de historia social y económica de América, 15, p. 7-41.

1998a, « Montañas sagradas, dioses solares e imágenes de AHAW. Iconografía de la escultura arquitectónica de la Acrópolis del Norte, Tikal (100 a.C.-200 d.C.) », Anales del Museo de América, 6, p. 95-109.

1998b, « Iconografía, significado, ideología: problemas y cuestiones en la interpretación actual del arte maya ", in Anatomía de una civilización: aproximaciones interdisciplinarias a la cultura maya, Sociedad Española de Estudios Mayas, Madrid, p. 65-85.

SATURNo William

2009, « Centering the kingdom, centering the king: Maya creation and legitimization at San Bartolo », in William L. Fash y Leonardo López Luján (eds.), The art of urbanism. 
How Mesoamerican kingdoms represented themselves in architecture and imagery, Dumbarton Oaks Research Library and Collection, Washington, p. 111-134.

SAturno William, Karl TAube y David Stuart

2005, « Los murales de San Bartolo, El Petén, Guatemala. Parte 1: El mural del norte », Ancient America, 7, p. 1-58.

SAturno William, Heather Hurst y Franco Rossi

2012, « Observaciones preliminares sobre la iconografía de la Acrópolis Los Árboles (12F19), Xultun », in Patricia Rivera Castillo y William Saturno (eds.), Proyecto arqueológico regional San Bartolo-Xultún. Informe de resultados de investigaciones de la temporada de campo no. 11, año 2012, Informe entregado al Instituto de Antropología e historia de Guatemala, Ciudad de Guatemala.

Segovia Pinto Víctor

1981, « Kohunlich: una ciudad maya del Clásico temprano », in Arturo Romano Pacheco, Carlos Navarrete y Victor Segovia Pinto (eds.), Kohunlich: una ciudad maya del Clásico temprano, San Ángel Ediciones, México, p. 211-295.

STONe Andrea J. y Mark Zender

2011, Reading Maya art: a hieroglyphic guide to Ancient Maya painting and sculpture, Thames \& Hudson, Londres.

Stuart David

1988, « Blood symbolism in Maya iconography », in Elizabeth Benson y Gillet Griffin (eds.), Maya iconography, Princeton University Press, New Jersey, p. 175-221.

2004, « The beginings of the Copan dynasty: a review of the hieroglyphic and historical evidence », in Ellen E. Bell, Marcelo A. Canuto y Robert J. Sharer (eds.), Understanding early Classic Copan, University of Pennsylvania Museum of Archeology and Anthropology, Philadelphia, p. 215-248.

2005, « Ideology and Classic Maya kingship », in Vernon L. Scarborough (ed.), A catalyst for ideas. Anthropological archeology and the legacy of Douglas S. Schwartz, School of American Research Press (School of American Research advanced seminar series), Santa Fe, p. 257-286.

2007, « Reading the water serpent as WITZ' », Maya decipherment, 13 de abril de 2007, https://decipherment.wordpress.com/2007/04/13/reading-the-water-serpent/, consultado en junio de 2015.

2013, " Report: name and image on two codex-style vessels », Maya decipherment, 21 de agosto de 2013, https://decipherment.wordpress.com/2013/08/21/reportname-and-image-on-two-codex-style-vessels/, consultado en junio de 2015.

Stuart David y Stephen Houston

1994, Classic Maya place names, Dumbarton Oaks Research Library and Collection, Washington.

Stuart David, Stephen Houston y John Robertson

1999, The proceedings of the Maya hieroglyphic workshop. Classic Mayan language and Classic Maya gods, University of Texas, Austin. 
TAUBE Karl

1985, « The Classic Maya maize god: a reappraisal », in Merle Greene Robertson y Virginia M. Fields (eds.), Fifth Palenque round table, 1983. Proceedings of the Fifth Palenque round table conference, June 12-18, 1983 Palenque, Mexico, The Pre-Columbian Art Research Institute (The Palenque Round Table series, 7), San Francisco, p. 171-181.

1992, The major gods on Ancient Yucatan, Dumbarton Oaks Research Library and Collection, Washington.

1996, "The Olmec maize god. The face of corn in formative Mesoamerica », RES: anthropology and aesthetics, 29/30, p. 39-81.

2000, The writing system of Ancient Teotihuacan, Center for Ancient American Studies (Ancient America, 1), Barnardsville/Washington.

2004, « Structure 10L-16 and its early Classic antecedents. Fire and the evocation and resurrection of K'inich Yax K'uk' Mo' », in Ellen E. Bell, Marcelo A. Canuto y Robert J. Sharer (eds.), Understanding early Classic Copan, University of Pennsylvania Museum of Archeology and Anthropology, Philadelphia, p. 265-295.

2005, «The symbolism of jade in Classic Maya religion », Ancient Mesoamerica, 16, p. 23-50.

TOKOVININE Alexandre

2013, 3D imaging report. Corpus of Maya hieroglyphic inscriptions, a project of the Peabody Museum of Archaeology and Ethnology, https://www.peabody.harvard. edu/node/821, consultado en junio de 2015.

VALDÉs Juan Antonio

1991, « Los mascarones del Grupo 6C-XVI de Tikal. Análisis iconográfico para el Clásico temprano », in Juan Pedro Laporte, Sandra Villagrán, Hector Escobedo, D. de González y Juan Antonio Valdés (eds.), II Simposio de investigaciones arqueológicas en Guatemala, 1988, Ministerio de Cultura y Deportes, Instituto de Antropología e Historia/Asociación Tikal, Guatemala, p. 129-145.

VALDÉs Juan Antonio y Federico FAHSEN

2007, « La figura humana en el arte Maya del Preclásico », in Juan Pedro Laporte, Bárbara Arroyo y Héctor Mejía (eds.), XX Simposio de investigaciones arqueológicas en Guatemala, 2006, Ministerio de Cultura y Deportes, Instituto de Antropología e Historia/Asociación Tikal/Fundación Arqueológica del Nuevo Mundo, Guatemala, p. 1160-1170.

Valencia Rivera Rogelio

2013, « Las múltiples caras de la divinidad. Complejos de dioses en la religión maya », in Alejandro Sheseña (ed.), Religión maya: rasgos y desarrollo histórico, UNICACH, México, p. 225-238.

Vargas Pacheco Ernesto

2010, « La legitimación de la realeza entre mayas del Preclásico tardío. Los mascarones de El Tigre, Campeche », Estudios de cultura maya, 36, p. 11-35.

Velásquez Garcia Erik

2010a, « Naturaleza y papel de las personificaciones en los rituales mayas, según las fuentes epigráficas, etnohistóricas y lexicográficas », in Andrés Ciudad Ruiz, 
Maria Josefa Iglesias Ponce de León y Miguel Sorroche Cuerva (eds.), El ritual en el mundo maya: de lo público a lo privado, Sociedad Española de Estudios Mayas, Madrid, p. 203-234.

2010b, « Los dioses remeros mayas y sus posibles contrapartes nahuas », in Laura van Broekhoven, Rogelio Valencia, Benjamin Vis y Frauke Sachse (eds.), The Maya and their neighbours. Internal an external contacts through time, Verlag Anton Saurwein (Acta Mesoamericana, 22), Markt Schwaben, p. 115-131.

2011, « La Casa de la Raíz del Linaje y el origen sagrado de las dinastías mayas », in Peter Krieger (ed.), La imagen sagrada y sacralizada. XVIII Coloquio internacional de historia del arte. Vol. 2, UnAM, Instituto de Investigaciones Estéticas, México, p. 407-434.

ZENDER Mark

2014, « The naming insight. Hieroglyphic names and social identity in the Pre-Columbian Maya », in Christophe Helmke y Frauke Sasche (ed.), A celebration of the life and work of Pierre Robert Colas, Verlag Anton Saurwein (Acta Mesoamericana, 27), Markt Schwaben, p. 61-74.

Zetina Sandra y Pilar GiRÁLdeZ

1999, « Proyecto Kohunlich. Informe al Consejo de arqueología. Temporada 1999. Vol. IV-A: Intervenciones de Restauración », informe resguardado en INAHDelegación Quintana Roo. 
